Cipango Cahiers d'études japonaises

$21 \mid 2014$

Nouveaux regards sur les arts de la scène japonais II

\title{
Made in Occupied Japan
}

L'avènement de l'industrie des biens durables et du design industriel au Japon

Made in Occupied Japan: The Birth of the Consumer Goods and Industrial Design Industries in Japan (1945-1955)

\section{Anne Gossot}

\section{(2) OpenEdition}

\section{Journals}

Édition électronique

URL : https://journals.openedition.org/cipango/2155

DOI : $10.4000 /$ cipango.2155

ISSN : 2260-7706

Éditeur

INALCO

Édition imprimée

Date de publication : 31 décembre 2014

ISSN : 1164-5857

\section{Référence électronique}

Anne Gossot, " Made in Occupied Japan », Cipango [En ligne], 21 | 2014, mis en ligne le 08 septembre 2016, consulté le 30 juin 2021. URL : http://journals.openedition.org/cipango/2155 ; DOI : https:// doi.org/10.4000/cipango.2155

\section{(c) (7) (8)}

Cipango est mis à disposition selon les termes de la Licence Creative Commons Attribution - Pas d'Utilisation Commerciale 4.0 International. 


\title{
Made in Occupied Japan \\ L'avènement de l'industrie des biens durables et du design industriel au Japon
}

\author{
Made in Occupied Japan: The Birth of the Consumer Goods \\ and Industrial Design Industries in Japan (1945-1955)
}

Anne Gossot

CLARE, CRCAO, université de Bordeaux Montaigne

\section{Introduction}

Au Japon, la modernisation-occidentalisation de la culture matérielle connaît une accélération radicale juste après la Seconde Guerre mondiale. Entamée sous l'ère Meiji, après le grand tremblement de terre du Kantō, elle a gagné les usages publics de la société, avant de s'arrêter au seuil de l'univers domestique, interrompue par la guerre. L'occupation du pays par les forces alliées occidentales, après la défaite en 1945, relance le processus avec une ampleur sans précédent. Elle est la première occasion d'une rencontre physique, concrète, avec l'Occident, pour la grande majorité de la population. La construction, à l'intention des familles des forces d'occupation entre 1946 et 1948, de milliers de logements entièrement aménagés à l'américaine constitue pour le Japon un apprentissage important du mode de vie occidental. Ce programme de construction, nommé Dependents Housing Program, redresse nombre de secteurs économiques en les dotant d'une infrastructure industrielle de pointe, apte à la production de masse d'équipements 
322 Cahiers d'études japonaises n²1

domestiques à l'occidentale. La conception de ces équipements américains, assurée par des Japonais sous la direction de designers américains experts, est une véritable école d'ingénierie industrielle. Elle dote le Japon d'une ingénierie du design d'un niveau de technicité inégalé par le passé. Dès la fin des années 1940, cette science du design permet aux Japonais de concevoir eux-mêmes des objets pour la vie à l'occidentale. Son fondement étant la conception de modèles standardisés, elle permet la production industrielle. En somme, avec l'occupant, non seulement l'industrie japonaise légère se reconstruit, mais elle hérite aussi d'un marché intérieur dynamique, avide de s'approprier le mode de vie américain, dont elle est désormais capable de produire elle-même les objets.

Ce sont les composantes et les modalités de ce phénomène que nous décrirons ici, en quatre parties. Nous commencerons par détailler les biens de consommation durables créés pour équiper les logements. Puis nous en analyserons l'impact sur les mentalités. Nous étudierons alors le processus selon le marché potentiel né au Japon, qui se mue bientôt en société de consommation de masse. Nous verrons enfin que cela se fait grâce à l'exploitation des brevets industriels du GHQ (General Headquarters) par la génération de designers formés aux techniques de pointe du design américain.

\section{Le logement des forces d'occupation}

\section{Les forces d'occupation civiles et militaires}

Après quinze années de conflits suscités par son expansionnisme en Asie orientale, le Japon se rend inconditionnellement aux puissances occidentales le 14 août 1945. L'ultimatum de Potsdam impose l'occupation du territoire japonais pour la durée nécessaire à la restauration de la démocratie dans l'archipel. Les États-Unis prennent la direction des affaires sur le territoire et nomment Supreme Commander for the Allied Powers (SCAP ou Commandant Suprême des Puissances Alliées) le général Douglas MacArthur(1880-1964). Le 28 août 1945 ${ }^{1}$, les premières troupes américaines arrivent sur le sol japonais.

1. Si cette date est souvent retenue par les auteurs, elle semble sujette à caution. Quoi qu'il en soit, une photo atteste que les premières troupes arrivent au plus tard le 30 août 1945. 
L'occupation commence officiellement le 2 septembre 1945, avec la signature de la reddition du Japon. Le 8 septembre, MacArthur entre dans Tōkyō.

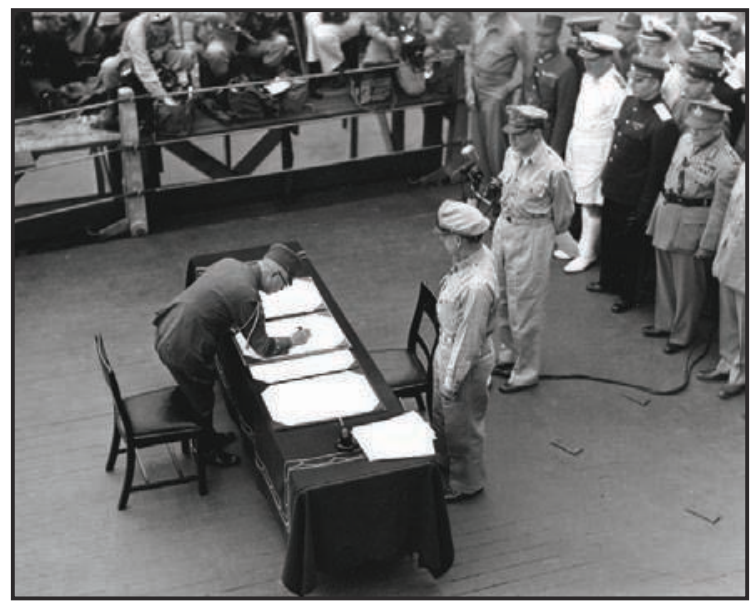

FIGURE 1.

Le général en chef de l'armée de terre Umezu Yoshijirō signant, face au général McArthur, l'acte de capitulation du Japon, à bord du cuirassé Missouri, dans la baie de Tōkyō, le 2 septembre 1945. Source : U.S. National Archives, photo $\mathrm{n}^{\circ} 80-\mathrm{G}-332701$

À l'automne 1945, près de 430000 étrangers occupent l'archipel. Fin 1945, la $6^{e}$ armée quitte le sol japonais, cependant seulement quelque 40000 militaires et civils du Commonwealth s'y installent. En février 1946, au moins 417000 occupants stationnent sur le territoire, dont plus de 45000 à Tōkyō. Militaires en majorité, ils sont partiellement remplacés, courant 1946, par des cadres civils : techniciens de la santé publique, du génie civil, de l'éducation, de l'administration, etc., dont un nombre important de femmes ${ }^{2}$.

2. Les effectifs décroissent par la suite : de 200000 en 1946 ils se stabilisent à environ 120000 en 1947. 
324 Cahiers d'études japonaises n²1

\section{Le logement des forces d'occupation civiles et militaires}

La première tâche des forces alliées est de mettre en place les infrastructures de l'occupation. Le 3 septembre 1945, premier jour de son entrée en fonction, MacArthur demande par la SCAPIN ${ }^{3} n^{\circ} 2$ au :

[...] gouvernement du Japon impérial de se préparer à fournir aux troupes d'occupation tous les bâtiments nécessaires : immeubles de bureaux, hôpitaux, logements, hangars militaires et entrepôts, commerces, infrastructures de transport et de communication [... attendu que,] dans la mesure du possible, tous les bâtiments seront fournis ignifugés, équipés de l'eau courante et du tout-à-l'égout, d'un système d'évacuation des ordures, de l'électricité, du chauffage, et qu' ils seront desservis par des routes praticables quelles que soient les conditions météorologiques.

日本帝国政府八占領軍二対シ其ノ為二適当二シテ且 其要求スル一切ノ建築物 提供スル準備 為スモノ卜ス 右要求八次ノ一般的種類即千事務所用建築物、病院、宿 舎、倉庫及貯蔵所、店舗、運輸及通信ノ施設 含么モノ 卜ス $[\ldots]$ 建築物八能フ限リ耐火建築二シテ水道、下 水、処理施設、電気、暖房装置习設備セラレ且如何ナル 天候二於テモ使用シ得ル道路二接スルモ/タルベキモ， トス午。

Le jour même, par un courrier à l'ambassade des États-Unis, le gouvernement du Japon impérial a prié la nation américaine de :

[...] bien vouloir épargner les logements et les bureaux de la population civile, pour se contenter des bâtiments de clubs privés et de salles publiques, des locaux administratifs des grands groupes industriels et des entreprises de fournitures militaires.

3. SCAPIN : Supreme Command for Allied Powers Instruction Note.

4. Koizumi Kazuko 小泉和子編 (dir.), Senryōgun jūtaku no kiroku 占領軍住宅の記 録 (Annales du logement des forces d'occupation), vol. 1, Tōkyō, Sumai no toshokan shuppankyoku 住まいの図書館出版局, 1999, p. 40-41. 
市民/住宅ヤ平民事務所ハトラナイデ、俱楽部、会館 ヤ財閥、軍需会社ノ事務所デ間二合ワセテ下サイ。市民 ノ御願デス

La requête du Japon sera en partie satisfaite.

Au cours du mois de septembre 1945, MacArthur sollicite du gouvernement du Japon impérial la mise à disposition de logements (environ 23 000), d'hôpitaux (au moins 9000 lits), de bureaux ( $95000 \mathrm{~m}^{2}$ entièrement équipés), ainsi que de toute l'infrastructure de production et de services indispensable à la vie quotidienne et aux activités des occupants. L'architecte américain Antonin Raymond témoigne :

The Army commanded everything that they needed: private houses, office buildings, clubs, theaters, barracks, anything that the Japanese Army or Navy or Air Force used, golf courses, tourist hotels, every facility that was anywhere near decent or which could be repaired. They ordered the Japanese Government to provide whatever they thought they needed on procurement, which meant without charge, so all the buildings requisitioned were being fitted with heating, plumbing, electricity and everything that the occupant could think of. This was done in a crude way in many cases and was extremely wasteful, as the curb of economy did not exist and it was considered a part of the humiliation of the enemy. ${ }^{6}$

La logistique de mise en œuvre et la totalité des frais de construction, de rénovation et d'équipement sont à la charge du Japon. L'effort matériel et financier sera titanesque.

En 1945, l'archipel est ruiné. Les cinq plus grandes villes - Tōkyō, Yokohama, Nagoya, Ōsaka, Kōbe - sont détruites dans une proportion variant de 50 \% à

5. SATŌ Yōichi 佐藤洋一, Senryōka no Tōkyō 占領下の東京 Occupation Forces in Tōkyō 1945-52 (Tōkyō sous l'occupation), Tōkyō, Kawade shobō shinsha 河出書房新社, 2006, p. 44.

6. Antonin Raymond, An Autobiography, Rutland (Vermont), Charles E. Tuttle, 1973, p. 204. 
$80 \%$. Sur les 4,8 millions de logements que comptait l'archipel en 1943, plus de 2 millions ont brûlé dans les bombardements et 600000 ont été intentionnellement détruits après le départ de leurs propriétaires. Le retour des familles de colons rapatriées en métropole après la reddition aggrave le problème : 4,2 millions de logements sont estimés nécessaires pour les accueillir. La majorité des bâtiments demeurés debout sous les bombardements est hors d'état : outre les parties détériorées par les projectiles et le feu, tous les éléments métalliques (tuyaux, etc.) ont été arrachés pour fabriquer le matériel de guerre, et les parties en bois démantelées par les civils pour se chauffer. Plus rien ne fonctionne.

À Tōkyō même, hormis les anciens quartiers de l'armée japonaise (Akasaka, Ōji, Itabashi, Akabane) et la baie de Tōkyō, ne demeurent à peu près intacts que les alentours du Palais impérial, naguère épicentre des affaires politiques et économiques de l'archipel. S'y dressent de monumentaux immeubles de pierre, sièges des grandes firmes japonaises, emblèmes de la puissance économique, à commencer par les banques et les assurances fondées dans le Japon de l'ère Meiji. Délibérément épargnés, semble-t-il, par les bombardements, situés en vis-à-vis du Palais impérial, ils deviennent le quartier général de l'administration de l'occupation. Le 17 septembre 1945, MacArthur installe ses bureaux dans l'immeuble de la Dai-ichi Life Insurance Company 第一生命館, qui, à partir du 2 octobre, abrite également le GHQ.

Les bâtiments réquisitionnés répondent à des normes variables selon le statut des individus auxquels ils serviront de logement.

\section{$\underline{\text { Le logement des officiers et des cadres civils célibataires }}$}

Outre l'administration des forces d'occupation, les immeubles des quartiers de Ichigaya, Marunouchi et Hibiya abritent les logements des officiers et cadres civils célibataires. D'importants travaux y sont engagés, dans l'urgence, pour les restaurer et les équiper, non seulement d'arrivées de gaz, d'électricité et d'eau, mais du chauffage, de cuisines et de sanitaires, dont salles de bain et toilettes à chasse d'eau - tous types d'équipement rares avant la guerre. Les étages sont aménagés en chambrées d'une à quatre personnes, et pourvus de restaurants et de services divers. Par exemple, le siège de la compagnie des Assurances maritimes de Tōkyō, Tōkyō kaijō 東京海上ビルディング (Old Kaijo Bldg), est restructuré en cham- 
brées de trois personnes pour les femmes officiers, avec « service de chambre, bar, salons, boutique de cadeaux, fleuriste, salle de bal... $\gg^{7}$, indique la légende d'une carte postale publicitaire présentant les chambres.

L’Imperial Hotel 帝国ホテル et le Dai-ichi Hotel 第一ホテル sont occupés par les hauts gradés. Les officiers militaires et civils logent au club des Jeunes du Japon 日本青年館; à la compagnie des Messageries maritimes 郵船ビル; aux assurances Meiji 明治生命ビル ; et ainsi de suite. Au total, environ 600 bâtiments sont réquisitionnés.

L'avenue Harumi, qui part du quartier de Marunouchi pour traverser Kasumi-ga-seki et Hibiya jusqu'à Tsukiji, recense tous les services occidentaux : commerces, commissaries et $P X^{8}$, hôpital, dispensaires, etc.

\section{$\underline{\text { Le logement des hauts gradés militaires }}$}

La plupart des hauts gradés est logée dans les villas de la grande bourgeoisie japonaise. En septembre, puis à nouveau le 11 novembre 1945, le SCAP envoie au gouvernement japonais une « Note sur la recherche d'habitations de style occidental dans la région de Tōkyō »(東京地区洋風住宅の調査に関する覚 書 Tōkyō chiku yōfū jūtaku no chōsa ni kansuru oboegaki), qui précise les critères requis pour les villas :

It is desired that the Imperial Japanese Government initiate without delay a Survey of all foreign type residence in the Tokyo area within forty-five minutes automobile time distance of the Imperial Palace $[\ldots]$

The minimum standards of quality will be as follows:

a) structurally sound.

b) utilities and heating plant in good condition.

7. SATŌ Yōichi 佐藤洋一, op. cit., 2006, p. 53.

8. Les deux termes désignent des commerces de type grande surface ou supérette fournissant, pour le $P X$ (abréviation de Post Exchange), les biens de consommation durables et services pour la vie quotidienne, et pour les commissaries, l'épicerie et les produits frais, dans les bases et les camps militaires américains. 


\section{CIPANGO}

328 Cahiers d'études japonaises n²1

c) clean.

d) interior finish in good condition.

e) minimum size will be six rooms, i.e. 2 bedrooms, 1 bath, 1 living room, 1 dining room, and 1 kitchen, with appropriate extra space such as closets, pantries, servants quarters, etc.

f) furnished and equiped with furniture and equipment in good condition. ${ }^{9}$

Cette liste témoigne du faible niveau d'information des Américains sur la situation du logement au Japon en 1945, à commencer par la conscience du faible niveau de pénétration de l'influence occidentale avant la guerre. Seules les résidences des magnats de l'industrie et de certains aristocrates, équipées d'une aile à l'occidentale ( yōkan 洋館) peuvent prétendre à un tel niveau de confort. Environ 700 de ces résidences sont réquisitionnées, dont celles, situées à Tōkyō, du baron Iwasaki Yatarō 岩崎弥太郎 (1835-1885), fondateur de la compagnie Mitsubishi ; du général et marquis Maeda Toshinari 前田利為 (1885-1942); et du prince amiral Shimazu Tadashige 島津忠重 (1886-1968). Les propriétaires de ces demeures reçoivent l'ordre de quitter les lieux, généralement dans la semaine qui suit la réception de l'avis. Ils doivent laisser le personnel et les équipements en place : meubles, appareils domestiques, ustensiles de cuisine, linge de maison,

9. Central Liaison Office, Memorandum for the Imperial Japanese Government: Survey of Foreign Type Residences in the Tokyo Area, Tōkyō, GHQ, 11 novembre 1945, p. 1-3. 
etc $^{10}$.

Souvent construites sur les vestiges d'un yashiki 屋敷 (résidence) de daimyō, ces résidences comportent d'élégants jardins et des bâtiments anciens au style raffiné. Comme elles ne satisfont pas entièrement les critères américains, elles reçoivent des transformations de grande ampleur. Les parois sont éventrées pour installer chauffage central, réseau électrique et tout-à-l'égout. Puis les nouveaux occupants, hermétiques souvent à l'esthétique japonaise, rustique et antihygiénique à leurs yeux, font ripoliner meubles et vieux lambris à la peinture blanche, et semer du gazon dans les jardins de mousse ${ }^{11}$.

\section{$\underline{\text { Le logement des troupes }}$}

Pour héberger les non-gradés, les bâtiments des troupes japonaises ne suffisant pas, le GHQ installe des camps de baraquements, tel Camp Drake. Il fait également

10. Voir, par exemple, le courrier adressé au gouvernement japonais par le SCAP sous le titre «Acquisition of the Baron Iwasaki Residence », le 8 avril $1946:$ : It is desired that the residence and grounds of Baron Iwasaki located at Kitori Machi number 1, Hongo-ku, Tokyo, be vacated and made available to an agency of General Headquarters of the Supreme Commander for the Allied Powers. 2. No furniture, furnishings or fixture presently in the residence will be removed until instructions for their disposition have been furnished by a representative of the Headquarters Commandant, General Headquarters of the Supreme Commander for the Allied Powers. 3. It is directed that the necessary renovation and repairs be accomplished to place the residence in condition for use by the Allied Forces and that furniture, furnishings and services required in connection with the residence be furnished. Detailed instructions pertaining to those requirements and the preparation of the residence will be furnished by the Headquarters Commandant, General Headquarters of the Supreme Commander for the Allied Powers. [...] »; texte reproduit dans SATō Yōichi 佐 藤洋一, op. cit., 2006, p. 20.

11. Voir à ce sujet les commentaires de Antonin RAYmond, op. cit., 1973, p. 205. 
venir des quonset huts ${ }^{12}$ par bateau des États-Unis. Ces baraques préfabriquées en tôle, à usage polyvalent, sont aménagées en dortoirs, en appartements, ou en équipements collectifs : dancing-hall, club-bar, etc. Au total, 888 quonset huts sont réparties à travers le Japon.

\section{Le logement des familles d'officiers civils et militaires mariés : le Dependents Housing Program}

Pendant les premiers mois de l'occupation, les cadres accompagnés de leur famille sont rares. En décembre 1945, le SCAP décide de faire venir les épouses et les enfants de tous les officiers, civils ou militaires. La mesure, politique, vise à faciliter l'intégration des mesures de démocratisation de la société japonaise, objectif central de l'occupation inscrit dans la déclaration de Potsdam. La vie de famille américaine servira d'exemple et d'émule pour moderniser les relations familiales et le couple japonais.

Les familles arrivent à partir d'août 1946. Un an plus tard, en septembre 1947, 7200 sont installées au Japon, dont 2000 (28 \%) à Tōkyō même. D’autres continuent à arriver par la suite. Il s'en trouve également un nombre important en Corée.

Trois catégories de logements les accueillent : des maisons et des immeubles réquisitionnés et réhabilités; des cités de quonset huts; des logements construits spécialement, suivant le Dependents Housing Program.

\section{Les maisons et les immeubles réhabilités pour les familles d'officiers}

Avant la guerre, les immeubles d'habitation construits en béton (résistant aux bombardements incendiaires) sont rares au Japon. Le tout premier immeuble d'habitation a été construit par Mitsubishi au large de Nagasaki en 1916, pour

12. Le terme kamaboko gata kōsha (littéralement: « bâtiment en forme de bâton de pâté de crabe »かまぼこ型校舎) est le surnom attribué par les Japonais aux préfabriqués en tôle, en forme de tunnel, mis au point en 1941 pour les besoins de la United States Navy sur les fronts de la Seconde Guerre mondiale. De dimensions standardisées : $6 \mathrm{~m}$ de large pour $15 \mathrm{~m}$ (ou $12 \mathrm{~m}$ ) de long, soit une superficie de $90 \mathrm{~m}^{2}$ (ou $72 \mathrm{~m}^{2}$ ), chaque bâtiment comporte un sol en bois et des murs intérieurs isolés par un revêtement de bois compressé. 
loger les ouvriers des mines de Hashima 端島 - aussi dit Gunkan-jima 軍艦島. Ont suivi, une décennie plus tard, quelques « cités d'habitation » expérimentales, conçues pour la nouvelle classe moyenne urbaine sur le modèle de l'habitat moderniste allemand ou français contemporain. Ces immeubles sont équipés de tous les services collectifs pour la vie quotidienne : école, commerces, restaurants, etc. Cependant, parce qu'il est synonyme de mode de vie à l'occidentale, l'immeuble de rapport en béton n'est guère parvenu à s'implanter dans l'archipel avant la guerre.

Dans le Tōkyō de 1945, seuls sept immeubles sont encore debout, dont le Bunka apāto 文化アパート (1926) et le Nonomiya apāto 野々宮アパート (1936). Ils sont réquisitionnés en vue d'être livrés réaménagés avant la fin 1947. C'est également le cas des grands hôtels modernes du Tōkyō de l'avant-guerre, la plupart dans le quartier de Kasumi-ga-seki 霞ヶ関, tel le Sannō Hotel 三王 ホテル, reconverti en 411 appartements sous le nom de «U. S. Naval Joint Service Activity Sanno Hotel ». Le nombre de logements étant insuffisant, l'État japonais réquisitionne d'autres bâtiments dont les maisons privées de style occidental.

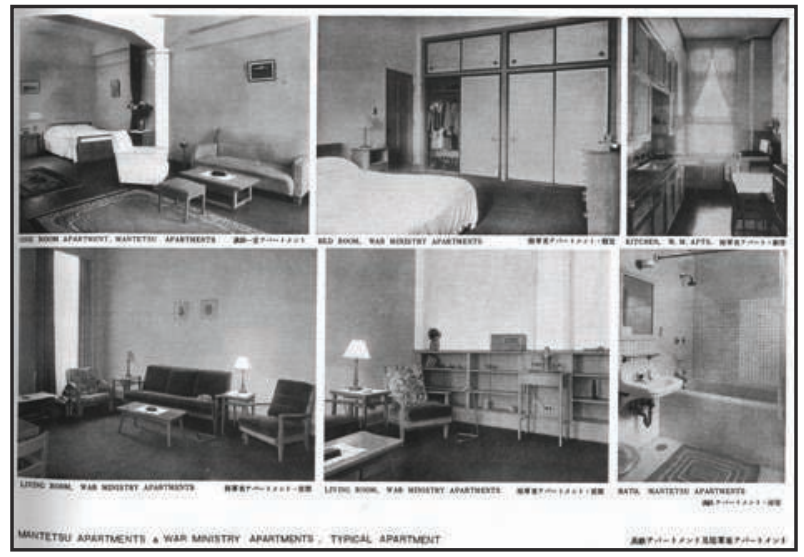

FIGURE 2.

Vue des pièces d'un appartement-type pour une famille, avec leurs équipements normalisés, à Pershing Heights パーシング・ハイツ, Tōkyō, 1948.

Source : Ouvrage GHQ Design Branch\&Shōkōsho KGSDS, 1946 
332 Cahiers d'études japonaises n²1

En dépit des extraordinaires efforts déployés, les familles américaines se plaignent du manque de confort. Les habitations, souvent isolées, sont mal desservies par les transports; les appartements, trop exigus ; etc.

Par ailleurs, avec l'arrivée en nombre croissant des familles, le nombre des logements disponibles ne suffit plus. Ainsi voit le jour un vaste programme de construction de cités résidentielles dotées de tout le confort moderne américain, à livrer clés en main à partir de la fin 1946.

\section{Les Dependents Housing Areas}

Le 31 janvier 1946, le Central Liaison Office du GHQ ordonne au gouvernement du Japon de préparer 20000 logements pour les familles, dont 16000 dans l'archipel et 4000 en Corée. Il émet un « Communiqué important » (Jūyō tsūchō tsuzuri 重要通牌綴) précisant que:

1. Les matériaux et tout ce qui sera nécessaire pour la construction des logements, mais aussi la fabrication et le transport, sont à la charge du gouvernement du Japon (le gouvernement fournira les matériaux et éléments dans les quantités demandées, le cas échéant, des matériaux de substitution de qualité équivalente, attendu qu'il doit informer immédiatement des quantités disponibles).

一、右宿舎用資材、材料、生産、運搬並ビ二之二要 スル労務及工事施工八総テ日本政府/負擔卜ス（必要資 材、材料/概數习提示シ之二對スル日本側供給可能ノ程 度並二代用品 7 必要卜スル場合八右/品質、数量 7 可及 的速二報告スル事习求ム）。

2. Les 20000 logements seront construits selon la répartition suivante : 15 \% dans l'île de Hokkaidō et dans la région du Tōhoku ; $35 \%$ dans les régions du Kantō, du Tōkai et du Kinki ; 32 \% à Shikoku et Kyūshū ; 18 \% en Corée (attendu que, concernant la Corée, seule la fourniture des matériaux est requise).

二、総数約二萬戸八北海道、東北地區一割五分、関 東、東海、近畿地區三割五分、四國、九州地區三割二 分、朝鮮一割八分ノ割合二テ建設セラルベク（但シ朝鮮 二付テ八資材ノ提供ノミ）。 
3. Les travaux débuteront au plus tard le $1^{\text {er }}$ avril.

ク。、其ノ日八遅クモ四月一日ヨリ工事開始ヨナスベ

4. En prévision des travaux de construction, le gouvernement du Japon est chargé de constituer tous les organismes nécessaires, et de rendre compte [au GHQ] de leur mode d'organisation [...].

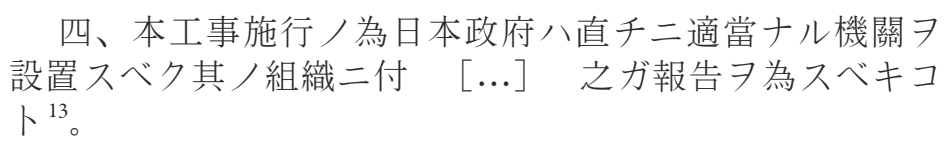

En somme, la conception générale de ce programme d'habitations et d'équipements est assurée, pour le compte du gouvernement du Japon, par l'Engineering Division, service du GHQ composé d'administratifs américains et d'une équipe technique : le Design Branch. L'équipe titulaire du Design Branch est japonaise mais elle est dirigée par un designer américain, le major Heeren Kruse. Pour la construction, le Japon crée un Comité de coordination national des entreprises du bâtiment, Nihon kensetsu kōgyō tōsei kumiai 日本建設工業統制組合, regroupant les principaux entrepreneurs encore en activité dans l'archipel. Le Comité est chargé de contacter et de coordonner les entreprises et techniciens contractuels, embauchés pour les travaux ${ }^{14}$.

Le 6 mars 1946, le Housing Program for Occupation Forces and their Dependents (SCAPIN 799) définit la nature des constructions, le type de matériaux utilisés, le nombre des meubles, appareils et ustensiles ménagers à fabriquer (950 000). Les directives sont transmises au gouvernement japonais, avec l'ordre de livrer le tout dans un délai d'un an, en mars 1947.

13. Koizumi Kazuko 小泉和子編 (dir.), op. cit., vol. 1, 1999, p. 41-42.

14. Voir infra, troisième partie : «Designed by America in occupied Japan ». 
334 Cahiers d'études japonaises nº 21

Les travaux commencent à l'été 1946 , sur les terrains réquisitionnés ${ }^{15}$. Dès la fin 1946, les premiers logements sont prêts ${ }^{16}$. Il faudra cependant plusieurs années pour que le programme du dependents housing soit entièrement réalisé. En 1949, à l'heure de son achèvement, le total des logements construits à travers l'archipel est de 9609 . Une seconde tranche ayant été décidée entre-temps, 2003 logements supplémentaires seront bâtis entre 1950 et 1951.

Le programme déborde largement le logement. Il s'agit d'édifier des villes à part entière, avec toute l'infrastructure nécessaire à la vie quotidienne. Une fois achevées, ces cités se présentent comme de véritables « Little America in Japan » closes sur elles-mêmes. Leur accès, contrôlé, est interdit aux Japonais non autorisés. Les Américains y vivent en autarcie, presque exactement comme aux USA.

Leur dimension varie, et la nature de leurs équipements avec. Mais le principe directeur est le même pour toutes : la banlieue pavillonnaire de la middle class américaine des années 1940.

Tōkyō accueille cinq dependents housing areas ${ }^{17}$, les plus vastes sur le territoire de l'archipel. Elles représentent un total de 2353 logements, soit plus du quart des logements construits pour les forces d'occupation.

Décrivons brièvement la deuxième par l'envergure : Washington Heights $\square$

15. Un rapport du ministère des Affaires étrangères Gaimushō 外務省 en date du 26 juillet 1952 indique qu’à Tōkyō même, 144 terrains ont été réquisitionnés pendant l'occupation : en majorité des parcs (comme le Hibiya kōen 日比谷公園), des stades et terrains de sport (Kokuritsu kyōgijō 国立競技場, Jingu kyūjō 神具球場, etc.), et d'anciens terrains militaires.

16. La fabrication des équipements et ustensiles domestiques n'est achevée qu'en 1947. Pendant les premiers mois de leur aménagement, nombre de familles « campent » dans leur logement, équipé de matériel japonais.

17. Outre Washington Heights, Tōkyō compte quatre dependents housing areas : Grant Heights (1 261 logements, alors la plus grande résidence militaire américaine dans le monde ; arrondissement de Nerima) ; Lincoln Center (50 logements ; quartier de Kasumigaseki) ; Jefferson Heights (70 logements ; quartier de Nagatachō) ; Palace Heights (156 logements aménagés dans des quonset huts, dans le quartier de Nagatachō). 
シントン・ハイツ ${ }^{18}$. Édifiée dans le quartier de Yoyogi, arrondissement de Shibuya, et répartie sur 92 hectares, elle compte 827 logements pour les familles d'occupants et 13 immeubles pour les employés de maison japonais. Elle est desservie par une cinquantaine de kilomètres ( 14,8 shaku 尺) d'artères intérieures et périphériques. Entourée par les bois, la cité bénéficie d'un air sain et d'un paysage agréable.

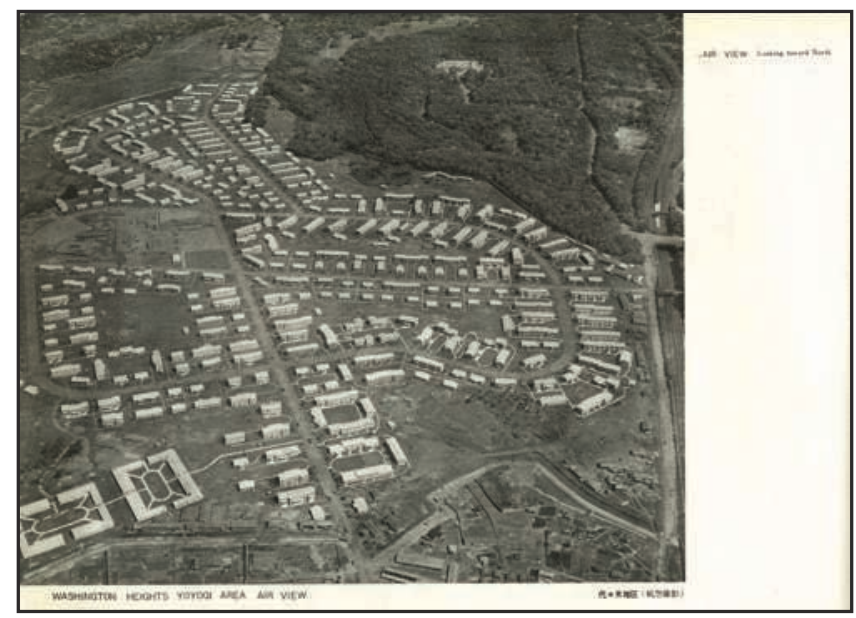

FIGURE 3-A.

La dependents housing area de Washington Heights ワシントン・ハイツ (827 logements familiaux), édifiée en six mois dans le quartier de Yoyogi, Tōkyō. Achèvement : mars 1947. Vue aérienne. Au nord-est (en haut à droite), le parc du sanctuaire shintô Meiji Jingū 明治神宮.

Source : Ouvrage GHQ Design Branch\&Shōkōsho KGSDS, 1946

18. Après sa restitution à l'État japonais en 1963, Washington Heights sera converti en village olympique et en équipements sportifs en vue des Jeux olympiques de 1964, puis, pour partie, en (l'actuel) parc de Yoyogi. 


\section{CIPANGO}

336 Cahiers d'études japonaises n ${ }^{\circ} 21$

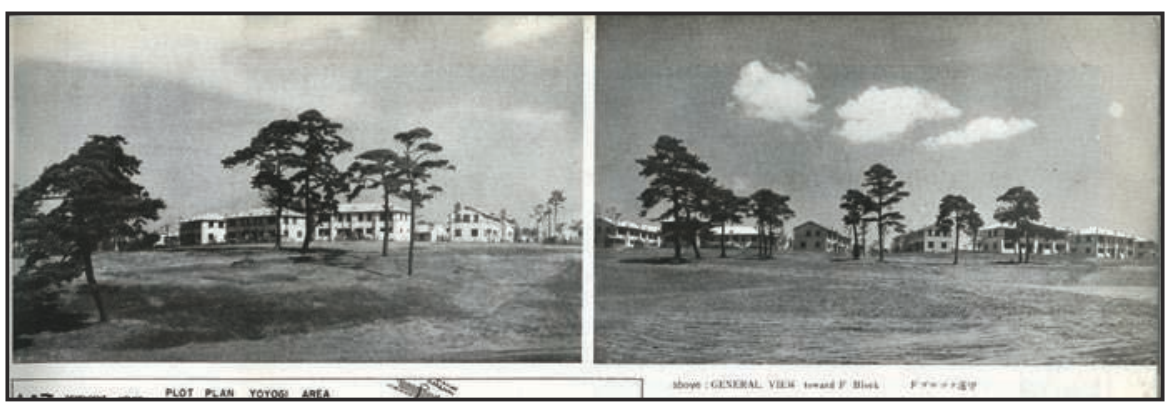

FIGURE 3-B.

Vue générale en direction des habitations.

Source : Ouvrage GHQ Design Branch\&Shōkōsho KGSDS, 1946

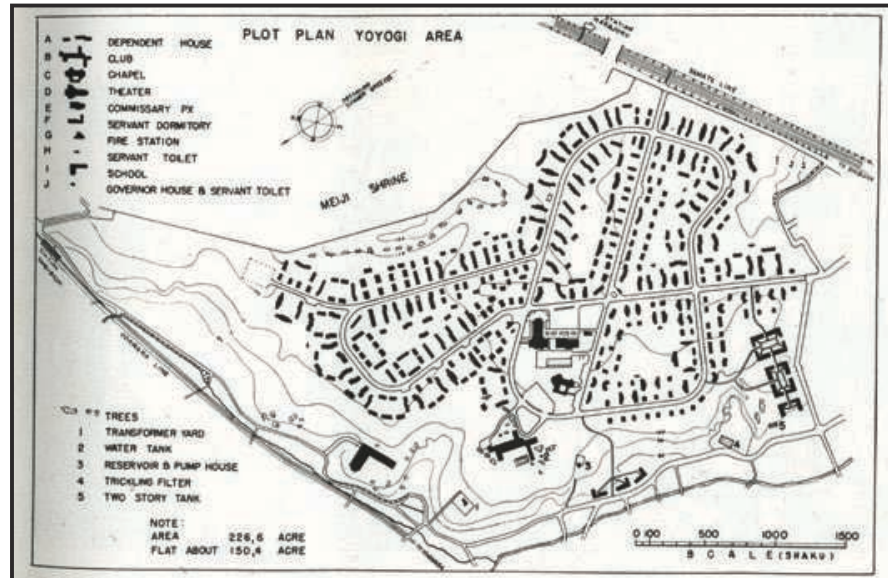

GENERAL VIEW OF HOUSE BLOCK F, YOYOGI AREA \& PLOT PLAN

FIGURE 3-C.

Plan général de la cité.

Source : Ouvrage GHQ Design Branch\&Shōkōsho KGSDS, 1946

La plupart est regroupée à l'ouest, entourée de pelouses bien vertes. Outre les logements, on y trouve tous les équipements collectifs nécessaires au mode de 
vie urbain : une salle polyvalente d'une capacité de 1000 places, équipée pour le cinéma, le théâtre et la musique ; une chapelle de 300 places ; un jardin d'enfants et une école primaire pour 780 élèves; un supermarché commissary- $P X$ pour 800 à 1000 familles; un club house équipé d'une piscine, d'une salle de bal, d'une bibliothèque-salle de lecture, d'une salle de jeu, d'un boudoir à jeux de cartes, d'un salon, d'un restaurant et d'un bar ; des parcs de jeux pour les enfants ; un terrain de golf; un terrain de base-ball ; des courts de tennis ; un dispensaire médical ; une station-service faisant garage d'entretien des véhicules; une caserne de pompiers ; un poste de police ; un service de transport par navettes; un réseau de tout-à-l'égout ; des bassins de rétention des eaux pluviales ; une station de pompage; des locaux pour l'administration de l'ensemble. 


\section{CIPANGO}

338 Cahiers d'études japonaises $n^{\circ} 21$

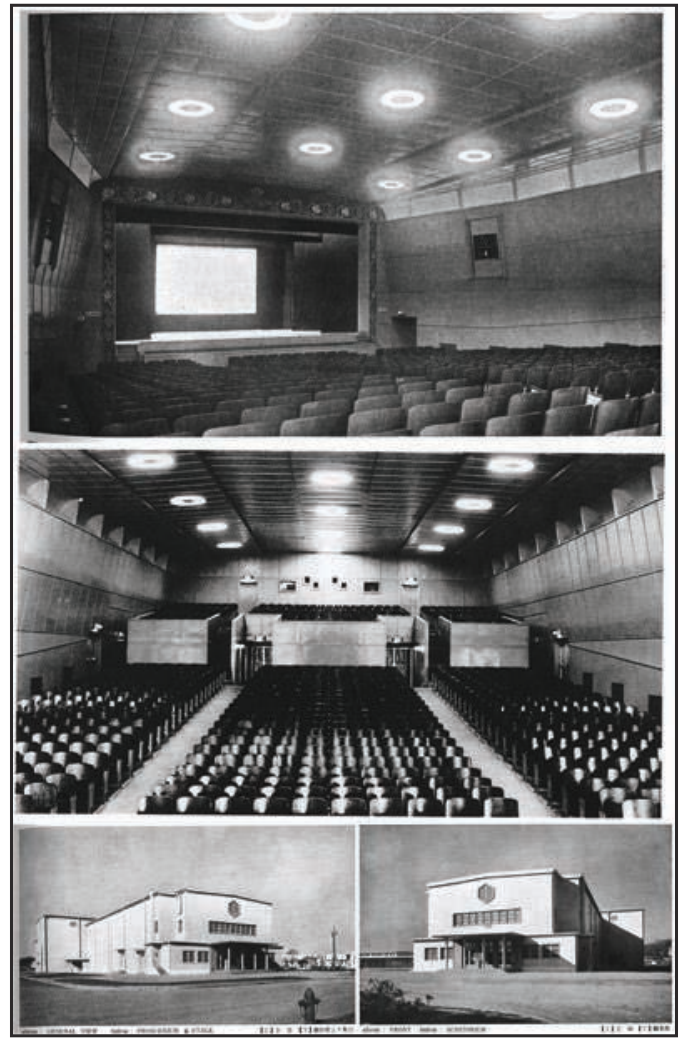

FIGURE 4.

Les équipements collectifs de Washington Heights. La salle polyvalente d'une capacité de 1000 places, équipée pour le cinéma, le théâtre et la musique. Source : Ouvrage GHQ Design Branch\&Shōkōsho KGSDS, 1946 


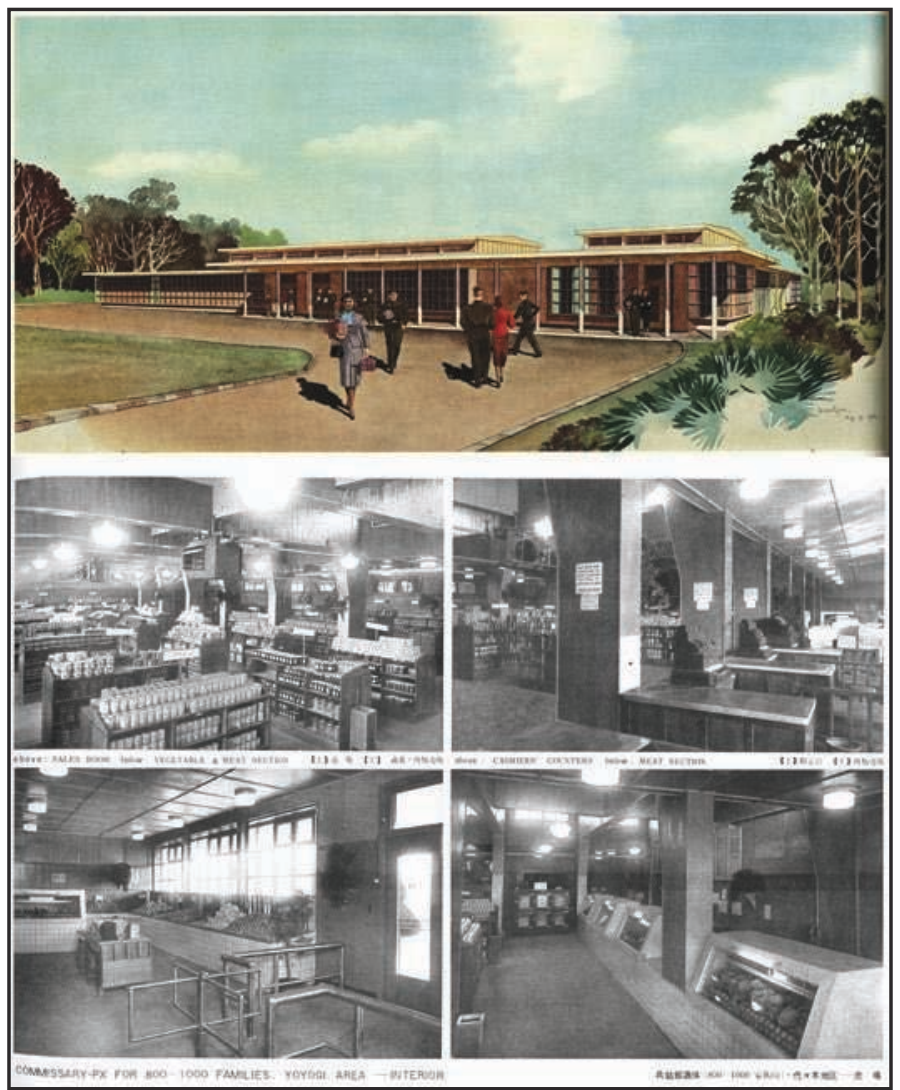

FIGURE 5.

Les équipements collectifs de Washington Heights. Le Commissary-PX, conçu pour 800 à 1000 familles. Ce supermarché offre tous les biens de consommation courante, de l'épicerie aux produits frais, et aux boissons, y compris l'entretien ménager.

Source : Ouvrage GHQ Design Branch\&Shōkōsho KGSDS, 1946 


\section{CIPANGO}

340 Cahiers d'études japonaises $n^{\circ} 21$

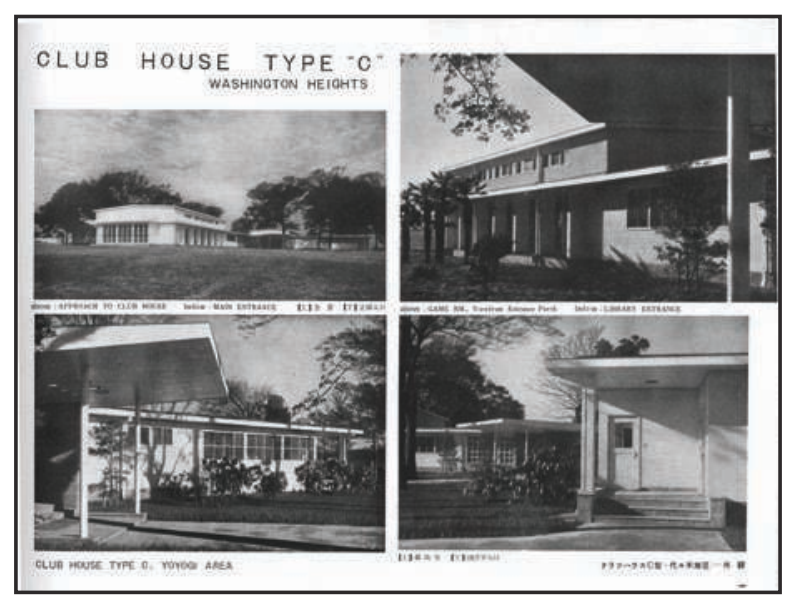

FIGURE 6-A.

Le club house (type « $\mathrm{C} »$ ) de Washington Heights, Tōkyō. Il est équipé d'une bibliothèque, d'une salle de jeu, d'une salle de bal, d'un restaurant et d'un bar. En haut : l'entrée principale et la salle de jeu; en bas : la salle de lecture et son entrée.

Source : Ouvrage GHQ Design Branch\&Shōkōsho KGSDS, 1946

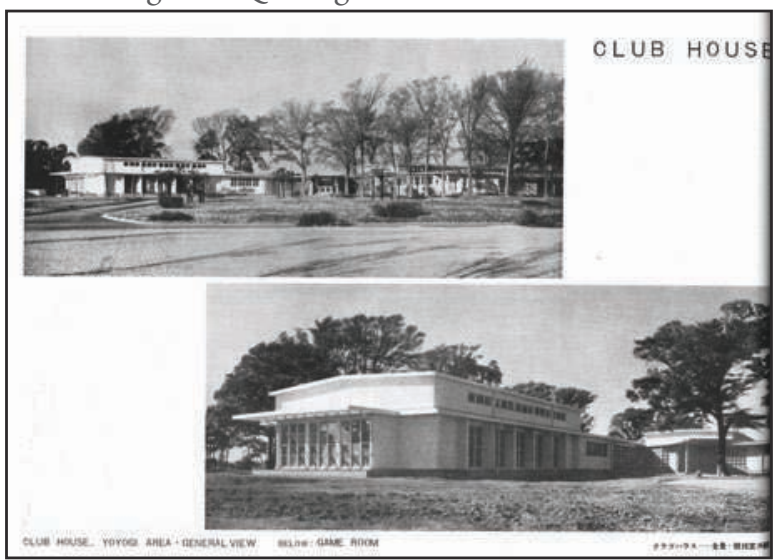

FIGURE 6-B.

vue d'ensemble; en bas : la salle de jeu.

Source : Ouvrage GHQ Design Branch\&Shōkōsho KGSDS, 1946 


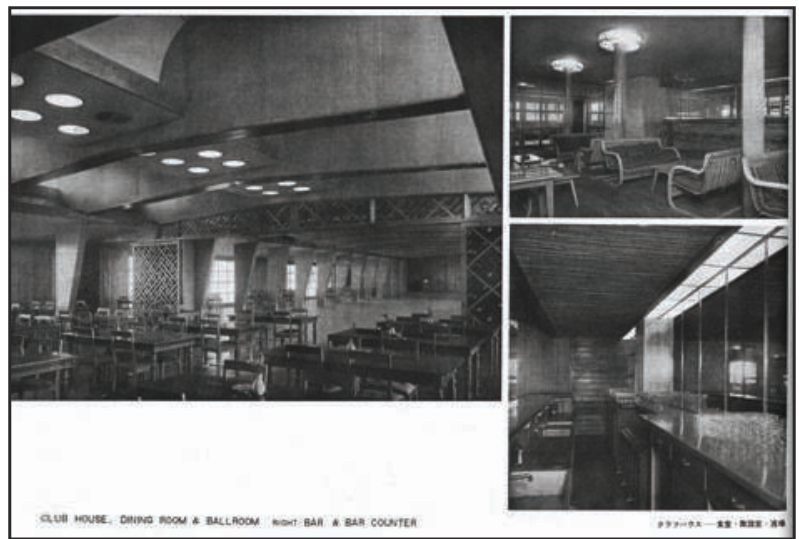

FIGURE 6-C.

À gauche : le restaurant; à droite : le bar (haut) et son comptoir (bas). Source : Ouvrage GHQ Design Branch\&Shōkōsho KGSDS, 1946

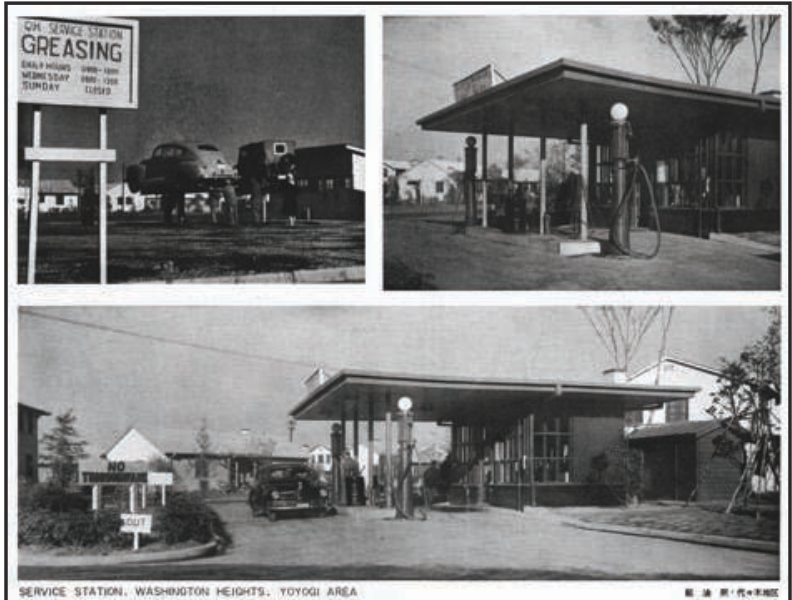

FIGURE 7.

Les équipements collectifs de Washington Heights. La station d'essence - garage d'entretien.

Source : Ouvrage GHQ Design Branch\&Shōkōsho KGSDS, 1946 


\section{CIPANGO}

342 Cahiers d'études japonaises n²1

La cité, édifiée en à peine six mois, est livrée clés en main le 6 mars $1947^{19}$. Les travaux de construction, dirigés par les architectes Heeren Kruse et Amito Takeo 網戸武夫, ont été effectués par les entreprises Kajima kensetsu 鹿 島建設, Shimizu kensetsu 清水建設 et Toda kensetsu 戸田建設. Ils ont coûté 800 millions de yens et mobilisé 2167000 ouvriers $^{20}$.

\section{$\underline{\text { Un habitat entièrement standardisé }}$}

Si les employés de maison japonais logent en dortoirs dans des immeubles, chaque famille d'officier bénéficie d'une maison particulière. Composée soit d'un unique rez-de-chaussée, soit d'un rez-de-chaussée et d'un étage, la maison est en bois, avec une façade crépie et un toit de tuiles. À Washington Heights, les maisons sont groupées en barrettes ou en quadrilatères de six à douze foyers, séparés par une pelouse commune soigneusement entretenue et équipée de balançoires et autres jeux pour les enfants.

L'aspect extérieur des maisons varie selon le modèle. Pourtant, selon Antonin Raymond, la qualité de la construction et leur aspect extérieur sont médiocres :

The result was far from happy. [...] The structures that the Army designed were of the common utilitarian type to be found all over the United States - that is, an uninteresting plan, $2 \times 4$ wood construction, stucco outside, plaster inside and roof tile on top. This was certainly not the thing to do in Japan, with danger of

19. Dans ses mémoires, l'architecte Amito Takeo 網戸武夫 note que les travaux, commencés en août 1946, se sont achevés en septembre 1947. Voir Amito Takeo 網戸武 夫, Kenchiku, keiken to moraru - Sone Tatsuzō, Chüjō Seiichirō, Nakamura Junpei, Kume Gonkurō to watashi 建築 経験とモラルー曾襧達蔵 中条精一郎 中村順平 久米権九郎と私 (Architecture, expérience et morale : Sone Tatsuzō, Chūjō Seiichirō, Nakamura Junpei, Kume Gonkurō et moi), Tōkyō, Sumai no toshokan shuppan-kyoku 住まいの図書館出版局, 1999, p. 167.

20. Aкıо Satoko 秋尾沙戸子, Washington Heights. GHQ ga Tökyō ni kizanda sengo ワ シントン・ハイツ・GH Q が東京に刻んだ戦後 (Washington Heights : le GHQ a imprimé dans Tōkyō les fondements de l'après-guerre), Tōkyō, Shinchō-sha 新潮社, 2009, p. 157-162. 
earthquakes and with the capacity for high-class workmanship by all the building trades. ${ }^{21}$

Construit avec la plus stricte économie de moyens tant au plan financier qu'au niveau des matériaux et techniques ou des délais, cet habitat est une brillante illustration du rationalisme fonctionnaliste, comme l'explique le GHQ :

It was necessary to design structures and communities which could be built anywhere in Japan by any contractor in Japan and yet stay within the limits of existing Japanese economy. These designs [...] are not visionary, theoretical solutions to a housing problem. These are structures to be built into communities by a country defeated and damaged in war $\left[\ldots . .{ }^{22}\right.$

Les normes de construction ont été publiées par le GHQ en juillet 1946. Intitulées Nihon oyobi chōsen ni okeru kazoku jütaku kensetsu hyōjun 日本及び 朝鮮における家族住宅建設標準 (Normes pour la construction d'habitations familiales au Japon et en Corée) et Rengōgun jütaku shinchiku kōji hyōjun shiyōsho 連合軍住宅新築工事標準仕様書 (Méthodes standardisées de construction pour les travaux des nouveaux logements des forces alliées), elles énoncent un certain nombre de principes :

- Les bâtiments seront construits avec les matériaux disponibles dans l'archipel, en respectant les usages japonais en matière de conception et de construction, tout en satisfaisant les critères du mode de vie américain ;

- La conception des bâtiments doit permettre les plus courts délais de construction, une quantité minimale de matériaux et des coûts tirés ;

- Les bâtiments doivent être constructibles aussi bien au Japon qu'en Corée ;

21. Antonin RaYmond, op. cit., 1973, p. 204.

22. Major Heeren S. Kruse, préface, in GHQ Design Branch Japanese Staff \& SHŌKŌSHŌ KŌGEI SHIDōSHO 商工省工芸指導所編 (dir.), Dependents Housing in Japan \& Korea デペンデントハウス 連合軍家族用住宅集図 (Le logement pour les familles des troupes d'occupation au Japon et en Corée), Tōkyō, 技術資料刊行会 F.E.C., 1948, p. 9. 


\section{CIPANGO}

344 Cahiers d'études japonaises n² 21

- La conception doit tenir compte également des contraintes de la production de masse, sans négliger la possibilité de relier les unités d'habitation entre elles ;

- Dans le cas des logements collectifs, la composition des logements doit être suffisamment variée pour éviter la monotonie.

En somme, la conception du dependents housing répond à des normes « universelles » au Japon et en Corée : il doit être constructible partout et utilisable par tous. Des superstructures au moindre élément du bâti, l'habitat est standardisé, tout est préfabriqué, modulaire et démontable. Sur ces points, le projet est une innovation en matière d'habitat civil pour le Japon. Il est suffisamment élaboré pour éviter la monotonie, inhérente à la standardisation, y compris au plan du paysage extérieur de la cité. Diverses solutions sont mises en place à cette fin, telles que l'interchangeabilité de certaines parties, par exemple l'installation du porche d'entrée d'un modèle de maison sur la façade d'un autre. Le plan intérieur du logement est lui aussi standardisé. Il existe trois formes-types $« \mathrm{~A} \gg, \ll \mathrm{B} », \ll \mathrm{C} \gg$, déclinables en neuf plans types de base - un par type de maison, dont chacun offre en plus diverses possibilités de variation dans le détail - selon le rang militaire et la dimension des familles.

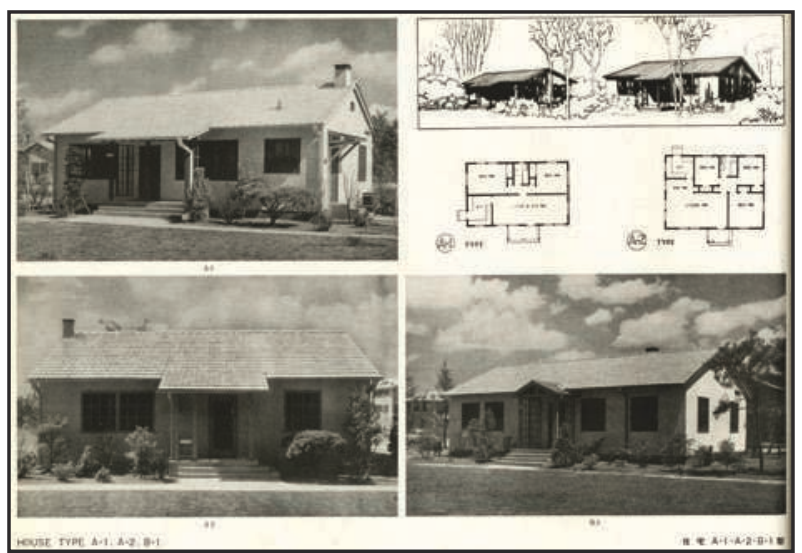

FIGURE 8-A.

Quelques-uns des modèles-types de dependents housing. Les plans-types «A-1 $\gg(2$ chambres), «A-2 » (3 chambres) et «B-1 $\gg(4$ chambres $)$ en rez-de-chaussée de plain-pied. Source : Ouvrage GHQ Design Branch\&Shōkōsho KGSDS, 1946 


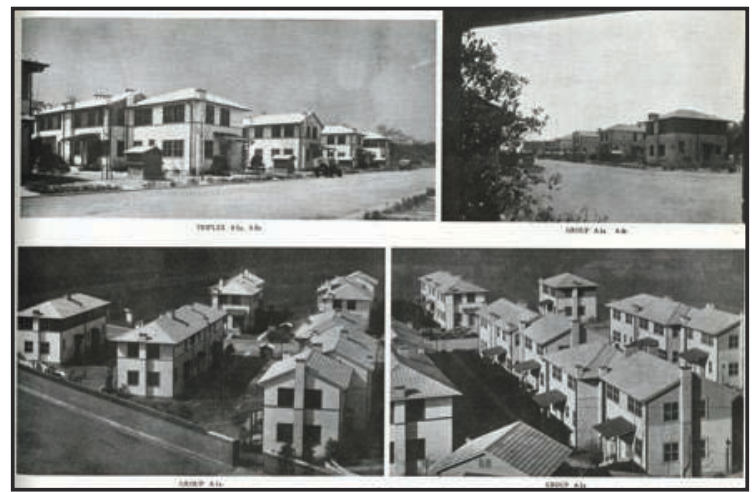

FIGURE 8-B.

Les plans-types en triplex (pièces de vie au $\mathrm{RdC}+$ chambres à l'étage).

Source : Ouvrage GHQ Design Branch\&Shōkōsho KGSDS, 1946

Les types $\mathrm{A}$ et $\mathrm{B}$ sont destinés aux familles de peu d'enfants - avec une chambre en plus si les enfants sont de sexe différent. Selon la forme et le plan, la superficie du logement varie de $95 \mathrm{~m}^{2}$ à $170 \mathrm{~m}^{2}$.

\begin{tabular}{|c|c|c|c|c|}
\hline \multicolumn{2}{|l|}{ type } & \multirow{2}{*}{$\begin{array}{l}\text { nombre d'étages } \\
\text { RdC }\end{array}$} & \multirow{2}{*}{$\begin{array}{l}\begin{array}{l}\text { superficie en } \\
\text { shaku } \text { 尺 }^{2} \\
\text { cuisine \& } \\
\text { sanitaires inclus }\end{array} \\
936\left(93 \mathrm{~m}^{2}\right)\end{array}$} & \multirow{2}{*}{$\begin{array}{l}\text { chambres } \\
\text { à coucher } \\
2\end{array}$} \\
\hline « $A »$ & A-1 & & & \\
\hline (pour $1^{\text {ers }}$ lieutenants & A-1A & RdC + 1 étage & $950\left(95 \mathrm{~m}^{2}\right)$ & $"$ \\
\hline & A-2 & $\mathrm{RdC}$ & $1064\left(105 \mathrm{~m}^{2}\right)$ & 3 \\
\hline & $\mathrm{A}-2 \mathrm{~A}$ & $\mathrm{RdC}+1$ étage & $1134\left(115 \mathrm{~m}^{2}\right)$ & " \\
\hline \multirow{4}{*}{$\begin{array}{l}\text { « } \mathrm{B} » \\
\text { (pour major colonel) }\end{array}$} & B-1 & $\mathrm{RdC}$ & $1170\left(120 \mathrm{~m}^{2}\right)$ & 2 \\
\hline & B-1A & $\mathrm{RdC}+1$ étage & $1344\left(135 \mathrm{~m}^{2}\right)$ & $"$ \\
\hline & B-2 & $\mathrm{RdC}$ & $1296\left(130 \mathrm{~m}^{2}\right)$ & 3 \\
\hline & $\mathrm{B}-2 \mathrm{~A}$ & $\mathrm{RdC}+1$ étage & $1670\left(170 \mathrm{~m}^{2}\right)$ & $"$ \\
\hline $\begin{array}{l}\text { « } \mathrm{C} » \\
\text { (pour la majorité) }\end{array}$ & $\mathrm{C}-1$ & $\mathrm{RdC}$ & $1485\left(150 \mathrm{~m}^{2}\right)$ & 4 \\
\hline
\end{tabular}

Source : GHQ Design Branch Japanese Staff \& Shōkōshō kōgei shidōsho 1948, p. 229 
346 Cahiers d'études japonaises $n^{\circ} 21$

Les aménagements sont eux aussi normalisés, jusqu'à la gamme des couleurs des murs, des rideaux ou des revêtements du mobilier. Meubles, sanitaires, vaisselle, linge de maison répondent à des modèles uniques, identiques dans tous les foyers. C'est la première fois de l'histoire, au Japon, qu'un projet de standardisation aussi radical voit le jour :

The Houses developed are actually something new. They are intended to provide average "western" living accommodations for two income groups and are to be built of materials obtainable currently anywhere in Japan and according to modified Japanese construction techniques. [They] are suitable for the greatest number of families of the Occupation Forces, but they can also be considered the forerunner to a new house and a new way of living for the Japanese people. ${ }^{23}$

\section{Les aménagements du Dependents Housing Program}

Chaque logement est livré équipé de tout le confort moderne. Le chauffage y assure une température constante de $23^{\circ} \mathrm{C}$. Toutes les pièces de vie sont meublées et décorées, avec rideaux aux fenêtres et tapis au sol, luminaires, radiateurs et ventilateurs. Par exemple, la pièce de séjour comprend une bibliothèque, des fauteuils, un canapé trois places, une table basse, un bureau, une table à téléphone et son tabouret, une table pliante pour jouer aux cartes (pouvant servir également de table à thé) avec ses quatre chaises pliantes, un lampadaire, un portemanteaux, un guéridon, un poêle à gaz.

23. Antonin Raymond, op. cit., 1973, p. 218. 


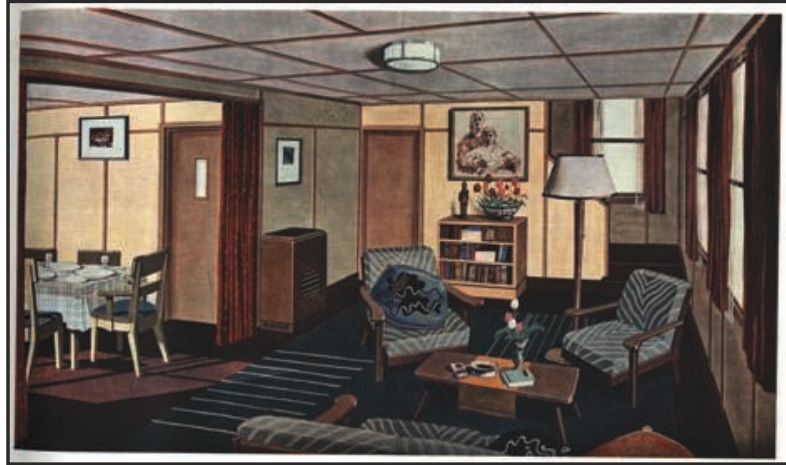

FIGURE 9.

Le dessin de la salle à manger - living-room de la maison de type « A-1 » à Washington Heights, Tōkyō, avec ses aménagements standards livrés clé-en-main. Source : Ouvrage GHQ Design Branch\&Shōkōsho KGSDS, 1946

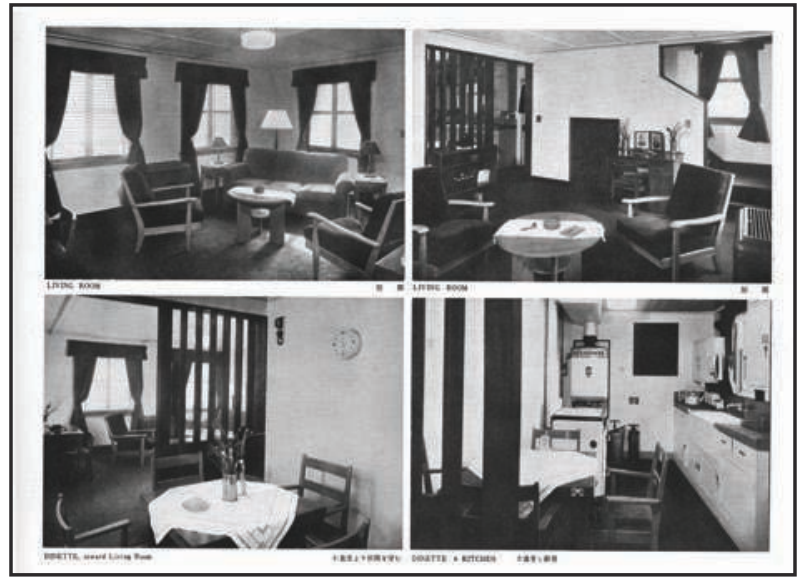

FIGURE 10.

Le living-room (haut) et la cuisine avec coin à repas de la maison de type « A-2A

(duplex) » à Washington Heights, avec ses aménagements standards. Source : Ouvrage GHQ Design Branch\&Shōkōsho KGSDS, 1946

Les chambres sont équipées de lits simple ou double avec matelas à ressorts, table de nuit, lampe de chevet, lampadaire, commode à vêtements, berceau, parc à jouer en bois, psyché, coiffeuse et tabouret dans la chambre des parents. 


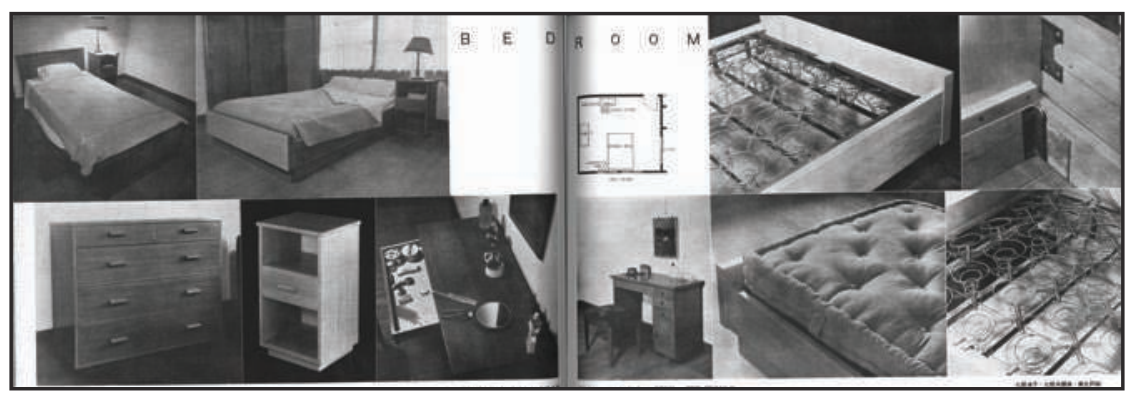

\section{FIGURE 11.}

Le mobilier standard des chambres. Lit simple ou lit double, table de nuit, lampe de chevet, penderie intégrée, commode, coiffeuse, tabouret, miroir, lampadaire, rideaux, oreillers, draps, taies d'oreiller et couvertures. La literie comprend un sommier à ressorts de qualité. Source : Ouvrage GHQ Design Branch\&Shōkōsho KGSDS, 1946

La cuisine est l'objet d'un soin tout particulier. Elle comprend la gamme complète de l'électroménager le plus moderne (cuisinière et chauffe-eau à gaz, réfrigérateur, four électrique, aspirateur, lave-linge, grille-pain, mixeur, hache-viande, gaufrier, cafetière électrique, cafetière expresso, bouilloire électrique, etc.), sans oublier la batterie de cuisine (moules à gâteaux et à tartes, fait-tout, cocotte-minute, etc.), ni les services de vaisselle et de couverts de table, deux en tout - l'un pour les jours ordinaires, l'autre, pour les réceptions, soit pour huit soit pour douze personnes. Le tout dans un luxe de détails extravagant : quatre types de couteaux, quatre de fourchettes, quatre de cuillères, cinq de cuillères à service, une pelle à tarte, une pince à glace, une pince à spaghettis, quatre types de verres à vin, deux pour l'eau, diverses carafes, des services de plats et assiettes (soit 61 ou 89 pièces : grandes assiettes/assiettes creuses/petites assiettes/assiettes à dessert/ coupelles creuses, ainsi que soupière, saladier, saucière, plats creux ou plats, etc.), avec tasses à thé et soucoupes, tasses à café et soucoupes, théière, pot à crème, pot à lait, sucrier, etc. 


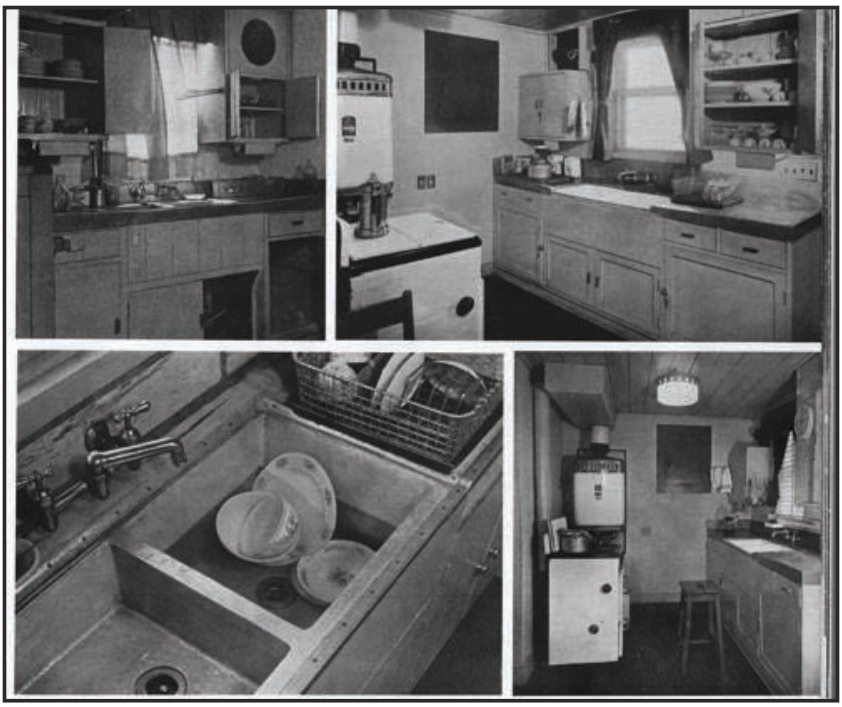

FIGURE 12-A.

La cuisine et quelques-uns de ses équipements standards. Évier, plan de travail, bloc de placards, placards et étagères muraux, vide-ordure, poubelle, tabouret, chaise, pendule murale, rideaux, vaisselle, batteries de casseroles, bouilloire, cafetière électrique, etc. Source : Ouvrage GHQ Design Branch\&Shōkōsho KGSDS, 1946

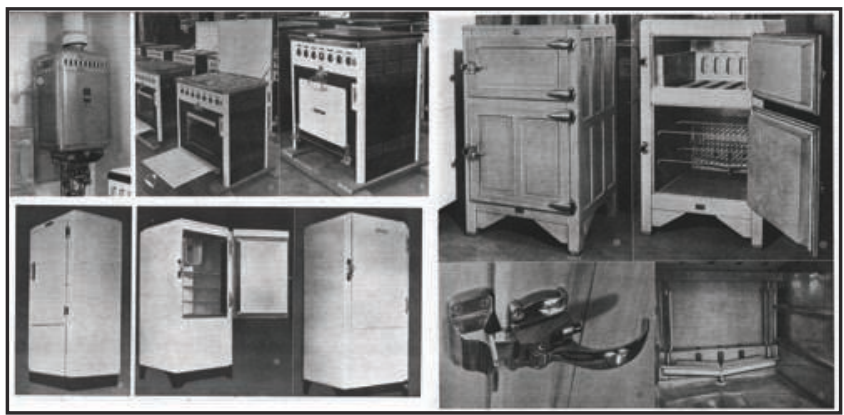

FIGURE 12-B.

Chauffe-eau au gaz; cuisinière électrique ; réfrigérateur ; armoire réfrigérante à la glace.Source : Ouvrage GHQ Design Branch\&Shōkōsho KGSDS, 1946 


\section{CIPANGO}

350 Cahiers d'études japonaises n² 21

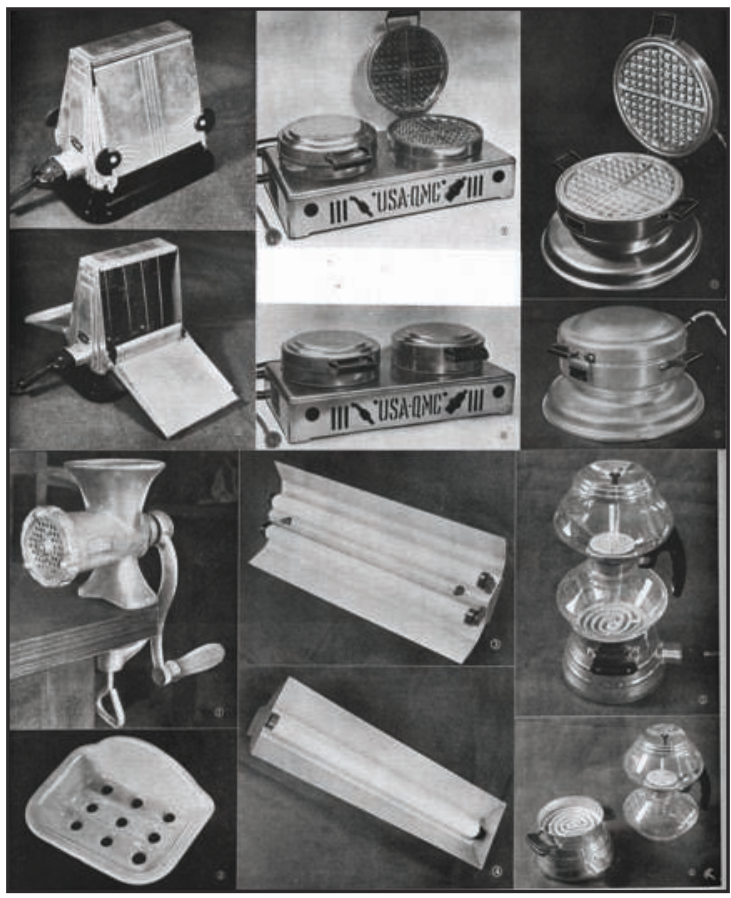

FIGURE 12-C.

Toaster électrique ; gaufrier électrique ; moulin à viande ; néons ; cafetière filtre ; etc. Source : Ouvrage GHQ Design Branch\&Shōkōsho KGSDS, 1946 


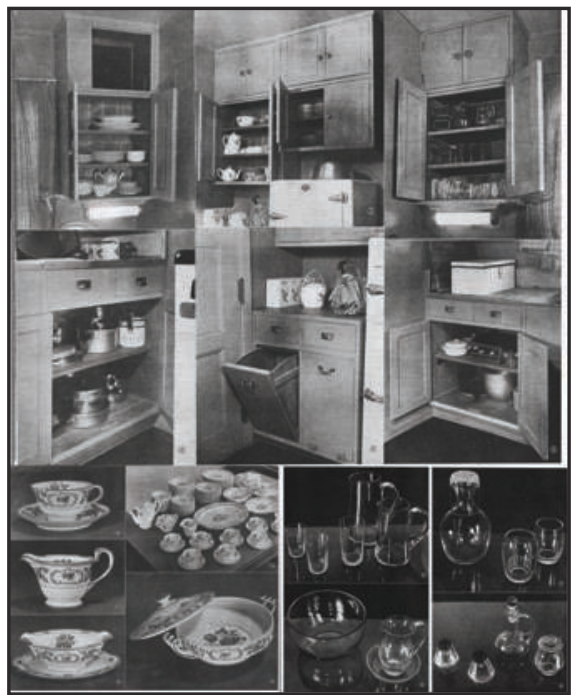

FIGURE 12-D. Placards à vaisselle ; vaisselle fine pour les réceptions : service à thé, service à dîner ; verres et objets en verre ; etc. La salle de bain est équipée avec le même soin, jusqu'aux serviettes et draps de bains. Source : Ouvrage GHQ Design Branch\&Shōkōsho KGSDS, 1946

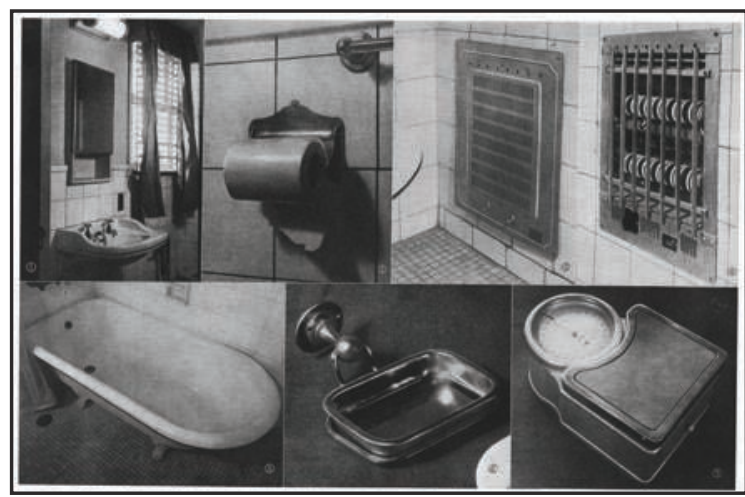

FIGURE 13. La salle de bain et quelques-uns de ses équipements standards.

(1) lavabo, placard de toilette, rideaux et stores ; (2) dévidoir à papier toilette ; (3) et (4) chauffe-bains ; (5) baignoire à l'occidentale ; (6) porte-savon; (7) pèse-personne. Source : Ouvrage GHQ Design Branch\&Shōkōsho KGSDS, 1946 


\section{CIPANGO}

352 Cahiers d'études japonaises n²1

Tout est fabriqué dans les meilleurs matériaux disponibles. Le mobilier est en bois. Dicté par le designer américain Kruse, le choix du bois va alors à l'encontre du goût des collaborateurs japonais, qui considèrent le tube en acier comme plus moderne. Mais le goût décoratif de la middle class américaine, synthèse de la tradition rurale vernaculaire et des styles classiques européens, récuse absolument le moderne, explique Kruse. Le bois est choisi parmi les variétés disponibles sur un marché profondément désorganisé. Pour le mobilier est ainsi retenu le chêne du Japon nara 楢, avec une finition au vernis, si besoin après teinture au brou de kaki, kaki shibu 柿渋. En dépit des contraintes, le confort est l'objet de l'attention la plus minutieuse. Par exemple, les dossiers des canapés et fauteuils sont rembourrés (ressorts) et tapissés, de même que leur assise et celle des chaises. Les accoudoirs sont en forme de « $S$ » afin de permettre aux Japonais de s'asseoir en tailleur, comme ils le font volontiers sur les fauteuils, et aux Américains de s'asseoir une jambe posée sur l'accoudoir - d'où également le dossier recourbé en arrière, voire à même l'accoudoir ${ }^{24}$.

24. Koizumi Kazuko 小泉和子編 (dir.), op. cit., vol. 2, 1999, p. 112. Designer des chaises du Dependents Housing Program, Akioka Yoshio 秋岡芳夫 raconte : « Moi qui n'avais encore guère utilisé de chaise jusque-là sinon à l'école, j'étais persuadé que la manière convenable de s'asseoir dessus était de se tenir le dos droit comme un $i$. C'est grâce aux démonstrations avec une vraie chaise et aux instructions du major Kruse et des designers du Design Branch du GHQ que j'ai appris, dans le moindre détail, comment utiliser une chaise quand on est chez soi, y compris à la manière mal élevée des Américains. » 学校 などでしか椅子を使ったことがなかった、いわば椅子の生活体験の貧しい僕 に、椅子にはお行儀よく真つ正面向きに座るものとばかり思い込んでいたぼ くに、椅子の家庭での使い方や、アメリカ流の，お行儀の悪い腰掛けの使い 方を、微に入り細をうがつて、現物を使つて教示、デザイン指導してくれた のもクルーゼや G H Q のデザインブランチのデザイナー達でした。(AkiokA Yoshio 秋岡芳夫, 《Shinchūgun-yō DH kagu no sekkei » 進駐軍用DH 家具の設 計 [La conception du mobilier pour le dependents housing des forces d'occupation], in ZaIDAN HōjIn KōGEI ZAIDAN 財団法人 ・ 工芸財団編 [dir.], Nihon no kindai dezain undōshi, 1940-nen kara 1980-nen 日本の近代デザイン運動史 1940年〜1980年 [Histoire du mouvement du design moderne au Japon, 1940-1980], Tōkyō, Perikan-sha ペりかん社, 1990, p. 10.) 


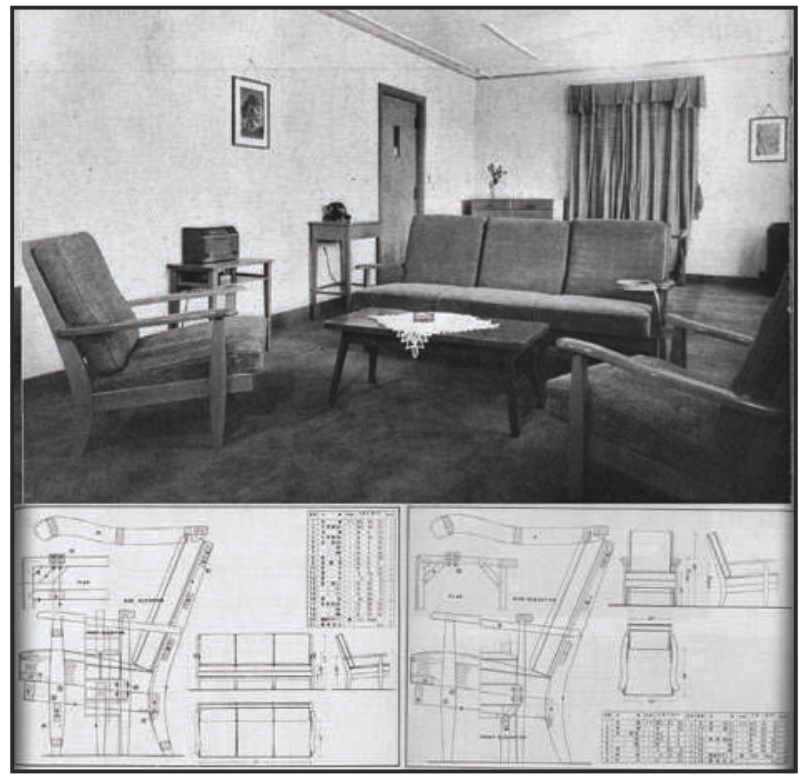

FIGURE 14.

Canapé et fauteuils de salon et leurs plans. Remarquez la courbure particulière des accoudoirs, dessinée pour permettre de s'asseoir en tailleur ou bien de poser confortablement les jambes dessus, raconte le designer Akioka Toshio 秋岡芳夫.

Source : Ouvrage GHQ Design Branch\&Shōkōsho KGSDS, 1946

Au total, 13118 logements à l'occidentale sont ainsi aménagés en un temps record dans l'archipel (9 609 logements dans les cités nouvelles, et 2621 dans les immeubles et maisons individuelles réquisitionnés) dont 3560 à Tōkyō. Leur aménagement nécessite la création de centaines de milliers d'ustensiles domestiques. Tous sont conçus et fabriqués au Japon, en l'espace de 18 mois environ.

Avant d'analyser plus avant la genèse de la production de ces équipements, et son rôle dans l'histoire du design au Japon, étudions d'abord l'impact des réalisations du Dependents Housing Program dans l'archipel. La découverte du mode de vie américain et de la culture matérielle qui en est le support, à travers ces logements et leurs aménagements, est un choc. Pour la majorité de la population japonaise, c'est la première confrontation avec ce qui, pour le monde entier d'alors, 


\section{CIPANGO}

354 Cahiers d'études japonaises n²1

représente la pointe de la modernité en matière de culture domestique. Quel en est l'impact sur les mentalités et sur les modes de vie ?

\section{Impact sur les mentalités et sur les modes de vie au Japon}

\section{État du logement et des équipements domestiques en milieu urbain avant 1946}

Avant la guerre, loin de partager le confort des villas modernes à l'occidentale, la grande majorité de la population en milieu urbain vit chichement, dans les logis sommaires et exigus légués par la tradition vernaculaire.

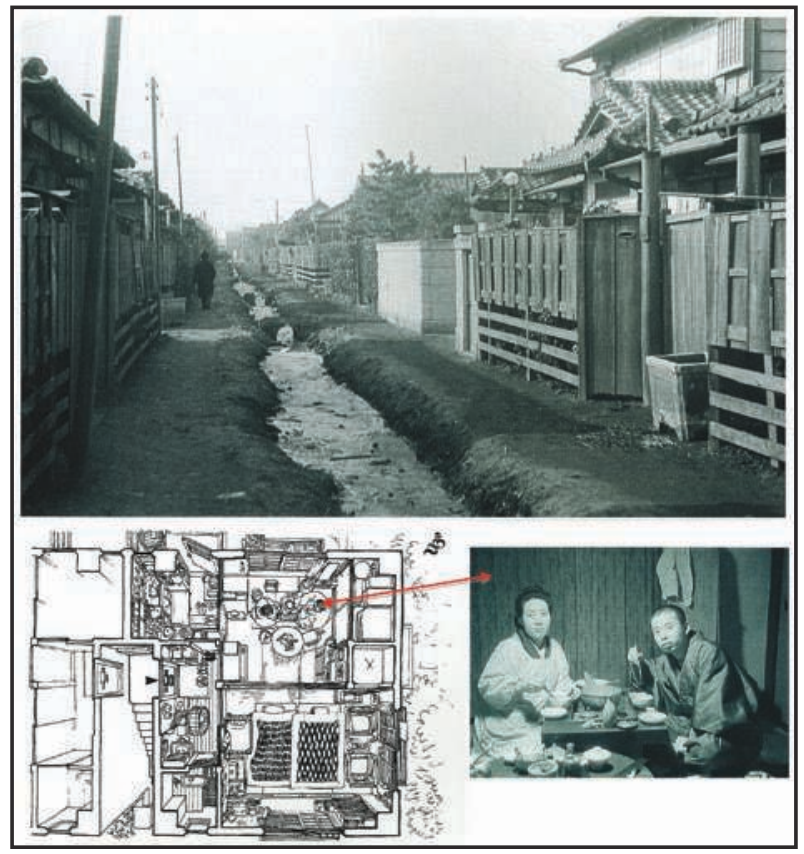

FIGURE 15.

Le logement urbain de la grande majorité de la population à Tōkyō avant la guerre, classes moyennes incluses. Des ruelles bordées de maisons en bois nagaya 長屋; un espace vital très exigu; le mode de vie hérité de l'époque d'Edo (1603 1868). Source : Nishiyama bunko, Archives NPO 西山文庫, «NPO 西山文庫 》 
Les grandes enquêtes sur l'habitat effectuées à l'automne 1941 par le ministère de la Santé et du Bien-Être, Köseishō 厚生省, et en 1942 sur l'habitat de Tōkyō ${ }^{25}$ par l'urbaniste Nishiyama Uzō 西山外三 (1911-1994) mentionnent les chiffres suivants : $94 \%$ des citadins vivent dans une maison individuelle (qu'ils louent dans $76 \%$ des cas) ; $6 \%$ dans des logements collectifs (foyers geshukuya 下宿屋, ou immeubles de rapport apātoアパート). La presque totalité des constructions est en bois.

$80 \%$ des logements ont une superficie inférieure à $37 \mathrm{~m}^{2}$ (24 tatamis), et dans $50 \%$ des cas inférieure à $23 \mathrm{~m}^{2}$ ( 15 tatamis). Une fois soustraits l'entrée, la cuisine, les placards à futon (oshiire 押し入れ) et les toilettes - la plupart des maisons n'ont pas de salle de bain - il reste $15 \mathrm{~m}^{2}$ d'espace vital dans un logis de $37 \mathrm{~m}^{2}$, soit deux pièces d'une superficie respective de $9 \mathrm{~m}^{2}$ (6 tatamis) et $6,5 \mathrm{~m}^{2}$ (4,5 tatamis).

Dans ces logements minuscules, « l'équipement est des plus frustes » note Nishiyama Uzō 西山外三 en 1943.

Le mobilier est presque entièrement à l'ancienne (wakagu 和家具). Quasiment tous les foyers possèdent deux meubles : la table basse pliante, chabudai ちゃぶ台 ( $94 \%$ des foyers) et la commode à vêtements tansu 箪笥 ( $93,5 \%$ des foyers). Près de $80 \%$ possèdent également un petit placard à vaisselle, shokki todana 食器戸棚, et une petite étagère pour les ustensiles du thé chadansu 茶箪笥. On note aussi la présence d'une commode à vêtements de type traditionnel wadansu 和箪笥 dans deux tiers des foyers. Seuls $28,7 \%$ des ménages l'ont remplacée par une armoire à vêtements de type européen ${ }^{26}$. Les salariés du secteur tertiaire, qui constituent le noyau des classes moyennes, sont les seuls à rêver d'acquérir le coûteux mobilier occidental, devenu depuis l'ère Taishō un marqueur de statut social. Ce modeste mobilier est complété par divers petits éléments (présents dans quatre foyers sur cinq) : brasero, étagère à chaussure, etc.

25. L'enquête, intitulée Les Modes d'habiter à Tökyō (Tōkyōshi sumikata chōsa 東京市住 み方調査), porte sur 14 quartiers des arrondissements de Mitaka 三鷹, Edogawa 江戸 川, Kamata 蒲田, Ōmori 大森, Katsushika 葛飾, Shinbashi 新橋 et Jōtō 城東. Cité dans Koizumi Kazuko 小泉和子編 (dir.), op. cit., vol. 2, 1999, p. 221-224.

26. Avant la guerre, l'usage du vêtement occidental se cantonne à peu près à l'uniforme de travail. $50 \%$ des foyers possèdent un siège, et $78 \%$, une table haute, sachant que, dans la majorité des cas, il s'agit d'une table de bureau et de sa chaise, destinées aux devoirs scolaires des enfants, sinon du maître de maison. 


\section{CIPANGO}

356 Cahiers d'études japonaises n²1

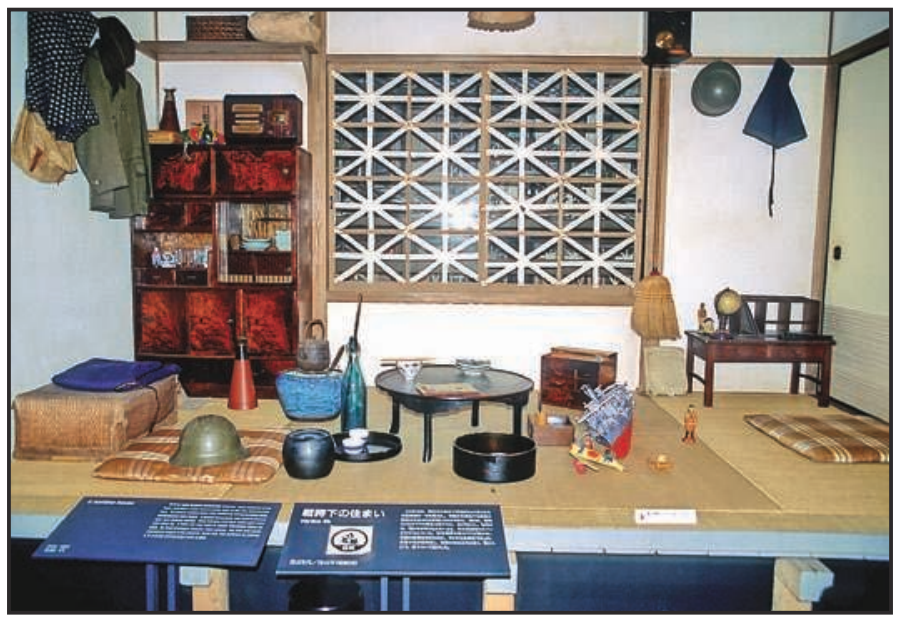

FIGURE 16.

Reconstitution récente d'un intérieur de logement urbain pendant la Seconde Guerre mondiale. Parents et enfants mangent et travaillent dans cette même pièce de 6 tatamis $\left(9 \mathrm{~m}^{2}\right)$, voire souvent y dorment ensemble. Les objets représentent l'essentiel des biens d'une famille japonaise de l'époque.

Source : Edo Tōkyō Museum 江戸東京博物館, cliché de Anne Gossot.

La production nationale d'équipements électroménagers, apparue vers 1930, ne couvre qu'un marché minuscule avant la guerre. Les appareils les plus répandus sont le ventilateur et le fer à repasser. Ils ne sont pourtant présents que dans $25 \%$ des foyers vers 1938. Ils demeurent des objets de luxe, taxés comme tels dans certains départements pendant la Seconde Guerre mondiale. Le prix exorbitant du réfrigérateur, de la machine à laver et de l'aspirateur - un réfrigérateur vaut le prix d'une maison - les rend hors d'atteinte pour la quasi-totalité de la population. Seule la radio a percé : $50 \%$ des ménages en possèdent une en $1944^{27}$.

27. Pour l'histoire de la diffusion des appareils domestiques avant la guerre, voir l'annexe $\mathrm{n}^{\circ} 2$ dans Anne Gossot, « "Gaz et électricité à tous les étages" : les débuts des industries électriques et électroniques », Les Cahiers d'Ebisu, n 1, 2010. 


\section{Dreaming the American Dream}

Bombardées à partir du printemps 1945, les grandes villes sont rasées. Commerces, usines, infrastructures routières... tout a disparu.

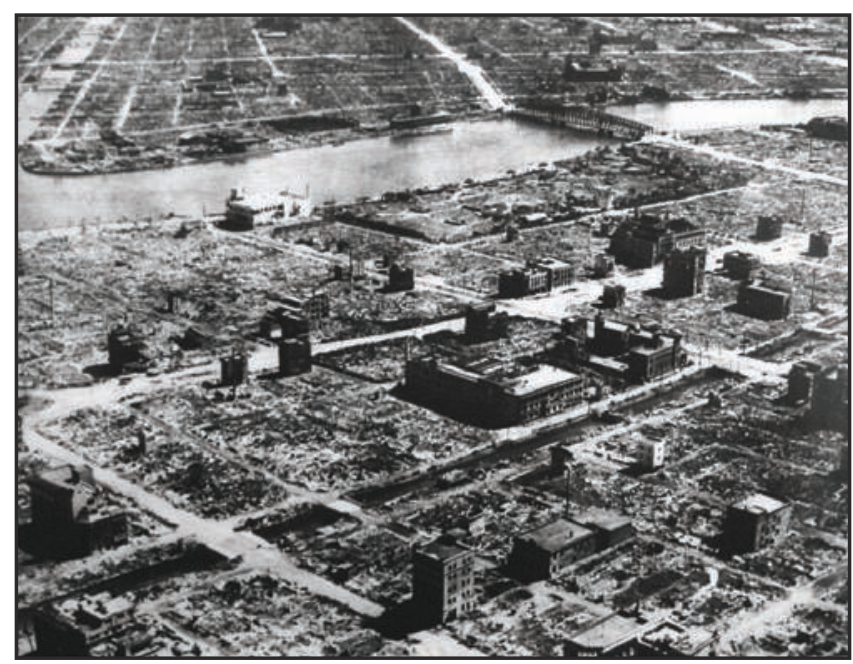

FIGURE 17.

Le paysage de Tōkyō après les bombardements incendiaires, en 1945.

Source : armée américaine

La population est repliée dans les bidonvilles érigés au-dessus des trous de bombes. 
CIPANGO

358 Cahiers d'études japonaises n²1

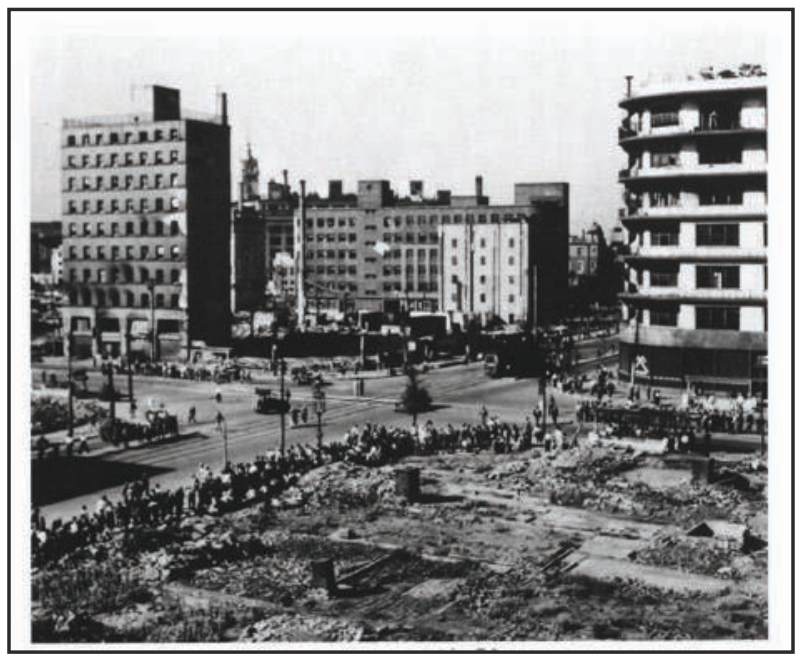

FIGURE 18.

Le problème du logement urbain pour la population civile dans l'immédiat après-

guerre.

Source : Nishiyama bunko, Archives NPO 西山文庫, «NPO 西山文庫 »

Tous meurent littéralement de faim, y compris les bourgeois de naguère. Les plus chanceux cultivent des lopins au milieu des ruines.

La rencontre avec le niveau de vie américain, alors le plus élevé du monde, a frappé les esprits. L'Occident fait rêver depuis l'ère Meiji. Pour la grande majorité de la population qui n'a pas fait le voyage outre-mer, l'occupation est la première occasion de se confronter à sa réalité. Regarder vivre au quotidien, « dans la rue », les Occidentaux présents sur le territoire donne une consistance nouvelle au fantasme.

Tout au long des années de guerre, la propagande antiaméricaine a infusé dans les esprits l'idée que les Américains étaient des «démons rouges 》 (aka oni 赤 鬼) malfaisants. La population est persuadée que quand ces démons débarqueront sur le sol japonais, ils tueront tout le monde. Aussi la rencontre avec les troupes d'occupation à partir d'août 1945 est-elle un choc, mais un choc positif : les jeunes recrues débarquent dans le calme et le silence; ils montrent un visage ouvert. Ils rient avec force et gestes quand ils tentent de converser le long des routes et des rues, distribuant des friandises à tous, ils fascinent par leur sourire et par la santé 
insolente de leur silhouette moulée dans un uniforme impeccable. Même leurs objets personnels les plus banals sont glamours : boîtes à sandwichs, magazines, stylos, etc., au design ultramoderne et aux couleurs intenses. En somme, dès les premiers jours de l'occupation, l'ennemi présente surtout un visage séduisant et attirant, qui redonne le goût de vivre et l'énergie pour tourner la page des années sombres.

La vie quotidienne des occupants dans l'archipel prend valeur de spectacle. Dans les services et les administrations du GHQ comme dans les logements, une armada d'employées de service assure l'entretien. Pour la plupart non anglophones, ces femmes sont souvent des mères de famille issues de la classe moyenne ordinaire (taishū 大衆) jusqu'alors peu habituées au travail salarié. Dans les dependents housing areas, elles logent sur place, en dortoirs. Leurs récits relayés par le bouche-à-oreille et par les médias rendent compte de la figure de la housewife, parangon moderne de la «bonne épouse et mère avisée »,ryōsai kenbo 良妻賢母, pivot de la middle class américaine : son rôle est de décorer la maison, de surveiller les devoirs des enfants, fêter les anniversaires, tenir les comptes du ménage, etc.

Le modèle de la « good housewife » est précisément l'idéal féminin ${ }^{28}$ qu'inculquent aux jeunes filles les institutions éducatives japonaises depuis les années 19101920, à commencer par les plus progressistes, qui entretiennent des liens étroits avec les pédagogues américains. Ce statut est alors considéré comme le moyen de s'émanciper du patriarcat ancestral qui fait de la femme une éternelle mineure. On y voit l'un des principaux moyens pour les femmes d'accéder à la respectabilité sociale - «ladies first! » - et, partant, à la citoyenneté. L'occupation ramène le sujet sur le devant de la scène, les réformes politiques du GHQ allant dans le sens d'une émancipation des femmes, avec le droit de vote en 1945, et l'interdiction de la discrimination des sexes en 1947.

Dans le même temps, les médias japonais font l'apologie de l'univers domestique américain. Le ministère de l'Industrie mène campagne auprès des fabricants, dans la presse spécialisée, pour la modernisation des aménagements de la cuisine,

28. Au Japon, la recette tient dans la formule dite 《sa-shi-su-se-so » : savoir coudre, SAiho 裁縫; avoir des manières policées, sHItsuke 仕付け; savoir cuisiner, suiji 炊事; savoir entretenir le linge, sEntaku 洗濯; savoir faire le ménage sōji 掃除. Voir YAMADA Shōgo 山田正吾, Kaden konjaku monogatari 家電今昔物語 (l'Électroménager jadis et naguère), Tōkyō, Sanseidō 三省堂, 1983, p. 60. 
pendant que la presse privée lance des magazines tels que Utsukushii kurashi no techō 美しい暮らしの手帖 (Pour un bel art de vivre) en 1947. Autre produit de cette nouvelle culture domestique, centrée sur le couple, la publication de la bande dessinée Blondie (USA, 1930-) dans l'hebdomadaire Shükan asahi 週間 朝日, à partir de 1946. Le feuilleton connaît un formidable succès, avec sa description de la vie d'un couple soudé et de ses enfants, dont le mari fait la vaisselle et dont les enfants s'expriment librement devant leurs parents. Des conceptions qui font rêver les femmes, prisonnières du système familial de Meiji (1868-1912) qui prévaut encore. La présentation de cette face de la culture américaine se renforce encore après la fin de l'occupation, avec, à partir de 1953, le lancement par la NHK de la télévision publique ${ }^{29}$ et des premiers programmes réguliers, les home dramas et les soap operas, feuilletons présentant le quotidien d'un foyer de la classe moyenne américaine, qui connaîtront une audience considérable. On se souvient, par exemple, de Uchi no mama wa sekai ichi うちのママは世界一 (Maman est un as), adaptation de The Donna Reed Show (USA, 1958-1966) diffusée au Japon entre 1959 et 1963, ou encore de Papa wa nandemo shitte iru パパは何でも知 つている (Papa sait tout), adaptation de Father Knows Best (USA, 264 épisodes, 1954-1960) diffusée de 1958 à 1964. Grâce aux médias japonais, le grand public s'initie non seulement aux règles de la vie sociale américaine, mais également - et c'est tout aussi important - au mode d'emploi de la culture matérielle occidentale : faire un lit, manier le couteau et la fourchette, tenir une tasse à thé, cuisiner un gâteau, mixer des légumes, dresser une table pour les invités, etc.

Le GHQ n'est bien évidemment pas en reste pour la diffusion d'informations sur la culture de l'occupant. OEuvrer à l'intégration du mode de vie américain relève de la stratégie d'instauration de la démocratie, nous l'avons dit. Dès 1947, le Natural Ressources Section (NRS) met en place et pilote, à travers le ministère japonais de l'Agriculture et des Forêts, une politique de réforme de la

29. La NHK ou Nippon Hōsō Kyoku 日本放送局, office de radiodiffusion et télévision national, est fondée en 1926. Les premiers essais de transmission télévisée en juin 1948 sont suivis par la création d'un office de transmission expérimental au sein des laboratoires de la NHK en 1950, puis, le $1^{\text {er }}$ février 1953, du lancement de la télévision publique. Cinq mois plus tard, le 28 juin 1953, est lancée la première chaîne privée de télévision : la Nihon Terebi 日本テレビ, créée grâce à la participation financière américaine et à une technologie de pointe importée des États-Unis. Du fait de leur prix élevé, les récepteurs télévisés n'étaient pas à la portée des bourses de la population, et la foule se massait autour des écrans disposés dans les cafés, les gares et les parcs. 
vie quotidienne en zone rurale, Nōson seikatsu kaizen undō 農村生活改善運動. Couvrant l'ensemble de l'archipel, elle vise avant tout à éradiquer la culture féodale ancienne, encore profondément enracinée dans les villages. Les populations rurales découvrent, avec émerveillement, les intérieurs américains, à commencer par la cuisine, devant des films conçus pour attiser le désir de conquête du miracle moderne $^{30}$.

Dans les grandes villes, la Civil Information \& Education Section (CIE) du GHQ diffuse l'information par divers moyens. Outre des projections de films, par exemple dans la cour des écoles primaires, 23 bibliothèques publiques de prêt sont constituées à travers l'archipel, dont deux à Tōkyō. Elles disposent de tous les magazines et publications américains les plus récents sur tous les aspects représentatifs de la culture américaine : sciences et technologie, vie quotidienne, mode, ou encore design et architecture. Parallèlement, la CIE aide des sociétés japonaises à organiser des expositions présentant l'univers domestique américain. Ce sont des sortes de « salons des arts ménagers » destinés aux designers, aux fabricants et aux vendeurs d'équipements domestiques, aussi bien qu’à la ménagère japonaise. Tel est le cas, par exemple, de l'Amerika seikatsu bunka アメリ 力生活文化 (La culture domestique aux États-Unis) en 1947 ; ou du Kaigai seikatsu shiryō bunka-ten 海外生活資料文化展 (La culture des objets domestiques outre-Atlantique) en 1948. L'une de ces manifestations a un retentissement particulièrement important : l'exposition Amerika ni manabu seikatsu zōkei-ten アメリカに学ぶ生活造形展 ( $S^{\prime}$ initier aux objets domestiques américains), qui se tient du 21 au 30 juillet 1948 aux grands magasins Mitsukoshi du quartier de Nihonbashi, à Tōkyō. On y visite, reconstitué à l'échelle, l'intérieur d'un logement du Dependents Housing Program avec son mobilier, ses appareils électroménagers, sa vaisselle, et son linge de maison. La reconstitution a été dirigée par Amito Takeo 網戸武夫, l'un des architectes du Design Branch. L'exposition se propose de « mettre en lumière, outre le confort, le caractère simple et pratique du mode de vie américain, pour qu'il serve d'exemple dans le futur $\gg^{31}$.

Du fait des faibles capacités de production pendant les deux premières années de l'occupation, les biens de consommation durables produits dans l'archipel sont réservés aux forces alliées. L'interdiction de commercialisation est levée à partir de

30. Koizumi Kazuko 小泉和子編 (dir.), op. cit., vol. 2, 1999, p. 225-226.

31. Ibid., p. 201-202. 


\section{CIPANGO}

362 Cahiers d'études japonaises n²1

1948. Les modèles de mobilier et d'électroménager qui arrivent sur le marché sont souvent calqués sur ceux fabriqués pour l'occupant. Si les masses japonaises n'aspirent guère à habiter dans des logements du Dependents Housing Program, trop éloignés du mode de vie traditionnel, en revanche, les équipements domestiques les font rêver. Les images du foyer « Made in America » ont ouvert un marché à l'horizon radieux.

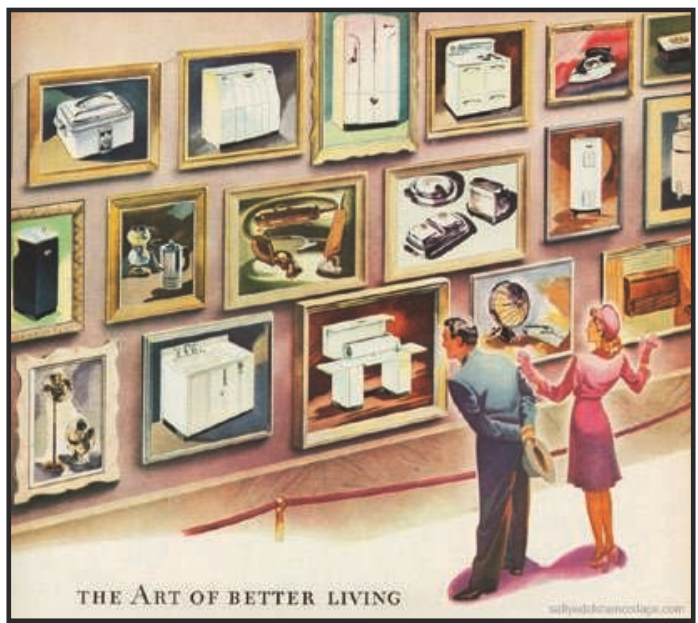

FIGURE 19. « The Art of Better Living » - Dreaming the American Dream (publicité Westinghouse, 1944). Source : Blog Envisionning the American Dream (EnvisioningtheAmericanDream.com)

L'heure de gloire de l'industrie japonaise de l'électroménager va bientôt sonner.

\section{« Designed by America in occupied Japan »}

\section{Le Japon à l'école du design US}

\section{$\underline{\text { Le Design Branch }}$}

Dans le cadre de l'occupation, l'État japonais est le maître d'ouvrage et le maître d'œuvre en titre, ainsi que le pourvoyeur des capitaux pour la totalité des infrastructures et équipements produits pour l'occupant : travaux, matériaux, transports, 
salaires, etc. Mais c'est le bénéficiaire de facto, à savoir le GHQ, qui décide de tout, de la conception des programmes et des plans, à la fabrication et à la distribution.

Au sein du GHQ, la conception des équipements relève du Design Branch, un service de l'Engineering Division. Le Design Branch travaille en lien avec ce dernier et avec le Quartermaster Section (QS, Juhinbu 需品部, Service de l'intendance militaire) du GHQ. Outre le bâti - construction du neuf, réhabilitation de l'ancien - le service conçoit les aménagements et les équipements nécessaires à la vie quotidienne (électroménager, sanitaires, mobilier, vaisselle, textiles).

Les travaux de conception sont dirigés par le major Heeren Kruse, architecte en chef du Design Branch. Âgé de 35 ans, il est originaire de Chicago, le grand centre américain de l'industrie du meuble. Avant de venir au Japon, il était designer en chef des équipements domestiques chez Sears, Roebuck and Co. ${ }^{32}$. Son équipe est réduite : outre deux architectes américains, elle compte une trentaine de designers japonais. Assistés d'une trentaine de « petites mains », dont des dessinateurs, ils forment le « Japanese Architectural Staff ». En fait de « designers » - la profession n'est pas encore née au Japon - ce sont des architectes ou des ingénieurs, quasiment tous employés réguliers de l'Industrial Arts Research Institute (IARI) qui rémunère donc leur contribution ${ }^{33}$. L'IARI est alors la seule « agence » d'art industriel existant sur le territoire. Ses ingénieurs sont l'élite des dessinateurs industriels dans l'ar-

32. Fondée en 1886 à Chicago, Sears, Roebuck and Co., plus connue sous le nom de Sears Robuck, fut pionnière et championne aux USA de la vente par correspondance. Pour ce spécialiste des articles de la vie quotidienne, les objets domestiques - dont le mobilier - occupent la place principale. La firme fournit par correspondance tout ce qu'il faut pour construire, équiper et rénover la maison. Elle possède ses propres usines. À partir de 1925, elle constitue son propre réseau de distribution en grandes surfaces (les actuels grands magasins Kmart).

33. L'Industrial Arts Research Institute (IARI), Shōkōshō kōgei shidōsho 商工省工芸 指導所 (Centre de recherche et de développement des industries manufacturées régionales), fondé en 1928 par le ministère japonais du Commerce et de l'Industrie, Shōkōshō 商工省, avait pour vocation première de rénover les techniques de fabrication de l'artisanat traditionnel dans la région du Tōhoku. L'architecte moderniste allemand Bruno Taut (1880-1938), employé par l'IARI en 1933-1934, a initié quelques-uns des ingénieurs à la réflexion et aux techniques de la conception industrielle. Puis les nécessités de la guerre ont fait de l'IARI le laboratoire de recherche et d'innovation sur les substituts de guerre pour la vie quotidienne, ainsi que sur l'industrie militaire - avions-leurres en bois, et autres articles pour le front. À l'heure de l'occupation, l'IARI est toujours l'unique organe actif au Japon dans le domaine de l'ingénierie de conception (c'est à dire du design). 
chipel. Ils se répartissent entre deux pôles, l'un en charge de projets d'architecture, l'autre du design, et passent de l'un à l'autre selon les nécessités du projet. Ces deux pôles sont coordonnés par l'architecte Shimura Tashichi 志村太七 ${ }^{34}$.

\section{Les méthodes de travail du Design Branch}

Les designers japonais travaillent sous la direction du major Kruse. Pour la conception du mobilier, leur tâche consiste à matérialiser des directives. Le major décrit, oralement, la nature des meubles à concevoir et le cahier des charges à remplir. Il remet à l'équipe un bon de commande écrit. Les Japonais dessinent le projet puis un plan au $1 / 10^{\mathrm{c}}$ qu'ils lui soumettent. Le major critique, corrige et fait redessiner jusqu'à ce que le projet lui convienne. S'ensuit l'élaboration d'un plan à l'échelle, à partir duquel un prototype est fabriqué en ville, et enfin l'établissement d'un plan définitif d'après le prototype. Toutes les étapes sont assorties d'allers-retours entre l'équipe japonaise et le major ${ }^{35}$. Au terme du processus, les plans définitifs sont envoyés aux fabricants de l'archipel, par l'entremise du ministère du Commerce et de l'Industrie.

Le processus d'élaboration des objets diffère pour les articles à peu près inexistants sur le sol japonais avant la guerre : l'ameublement (rideaux, tapis, linge de maison...) ; les appareils sanitaires (baignoire, lavabo, toilette...) ; les lampes ; les ustensiles ménagers (objets de cuisine, vaisselle de table, petit électroménager...) ; et les gros appareils (chaudière, radiateur, réfrigérateur, cuisinière...). Pour ce type d'articles, le GHQ importe des modèles depuis les États-Unis. Les ingénieurs japonais les analysent, en tracent les plans puis les retravaillent pour les adapter aux besoins. Ils s'aident de catalogues américains, dont ceux de la firme Sears \& Roebuck, qu'ils font venir à cet effet.

Quantité d'obstacles, tous complexes, contreviennent à l'avancée du projet, à commencer par la barrière linguistique : les langues anglo-saxonnes, symboles des

34. Né en 1890, Shimura Tashichi 志村太七 parlait l'anglais et connaissait l'architecture américaine pour avoir étudié à l'université de Harvard (Mass., USA), dont il était sorti diplômé en 1921.

35. Voir KAnEko Tokujirō 金子徳次郎, « Amerika no kagu wo Nihon de tsukuru koto - kurūze shōsa wo chūshin ni »アメリカの家具を日本で作ることークルーゼ少 佐を中心に (Fabriquer du mobilier américain au Japon : autour du major Kruse), Kögei nyūsu工芸ニュース (L'actualité des arts industriels), vol. 14, nº 2, octobre 1946, p. 18-23. 
puissances ennemies, ayant été bannies durant les années de guerre, le Japanese Architectural Staff ne parle pas l'américain. La terminologie des objets, notamment, pose problème. Souvent, le major Kruse désigne oralement un objet sous un nom différent de celui figurant sur le bon de commande final : comment savoir que « psyché » désigne un miroir, et « sofa », un canapé ? S'y ajoutent les difficultés techniques. Comment concevoir la forme d'un meuble ou d'un ustensile domestique qu'on n'a jamais vu et a fortiori utilisé ? Comment rendre confortable un fauteuil dans lequel on ne sait absolument pas comment s'asseoir, et qui est destiné à un utilisateur américain en moyenne plus grand de douze centimètres, dont une dizaine rien que pour les jambes ${ }^{36}$ ?

La conception de tous les équipements domestiques tient compte des contraintes en présence. L'État japonais, qui finance, est exsangue. L'archipel ne dispose pas de matières premières. Les capacités productives du pays sont au plus bas : $6 \%$ de ce qu'elles étaient en 1940. Dans les rares ateliers encore debout, les machines ont été recyclées en canons, ou bien elles n'ont pas servi depuis des années ; les techniciens, évacués ou mobilisés, ne sont pas encore rentrés; le plus souvent, les ouvriers n'ont jamais fabriqué ni mobilier ni appareils ou ustensiles ménagers occidentaux. S'ajoute la faiblesse des capacités électriques dans l'archipel qui, déjà réduites avant la guerre, sont maintenant proches du néant. Indispensables pour l'industrie, elles conditionnent également la qualité du mode de vie occidental. Pendant un certain temps, les Américains devront se passer d'appareils électriques tels que le réfrigérateur. Il en va de même pour les infrastructures telles que les réseaux électriques à haute tension, le tout-à-l'égout, ou le chauffage. Elles étaient rares avant la guerre en zone urbaine (habitations privées comme bâtiments publics) car souvent considérées comme superflues. En 1945, le Japon ne dispose pas de techniciens capables d'installer les chaudières et autres appareils considérés comme « indispensables » aux États-Unis.

36. L'architecte Amito Takeo 網戸武夫 rend compte de la méthode en ces termes : « Les meubles et objets dessinés pour le dependents housing ont été conçus par nous, et non pas selon les consignes des Américains. C'est nous qui les avons conçus, nous qui les avons imaginés. Sachant, bien sûr, que sur le plan matériel, ils se fondent sur ce que nous a appris l'observation des objets américains. » Voir AмIто Takeo 網戸武夫, op. cit., 1999, «Appendix », p. 3. 


\section{Une initiation accélérée à la standardisation industrielle}

Le cahier des charges est dense, les obstacles massifs, les délais brefs. La solution du « rationnel et efficace » s'impose. L'approche rationaliste convient, du reste, aux méthodes du major Kruse. Il a une prédilection pour la sobre sensualité organique du mobilier scandinave, d'un Alvar Aalto (1898-1976) par exemple. Encore mal connu au Japon, le mobilier scandinave des années 1930 ne demeurera qu'une lointaine référence d'arrière-plan dans le présent programme.

Une caractéristique majeure de l'approche rationaliste-fonctionnaliste est d'aborder la conception des objets en termes d' « objets types » répondant chacun à un « besoin type ». Le designer se doit d'établir, en priorité, la typologie des besoins liés à la vie quotidienne, en analyser les principes structurants, pour les caractériser et les hiérarchiser. Par exemple, concernant la fonction « s'asseoir », les besoins types sont : la détente (chaise longue); la vie sociale (fauteuil); le travail (chaise de bureau à accoudoirs ou tabouret d'usine); le repas (chaise de table). Le nombre de besoins types retenus dépend de divers facteurs, dont les moyens engagés pour le projet. Une fois la tâche achevée, le designer conçoit une forme - un modèle - qui remplisse au mieux le cahier des charges de chaque besoin. Pour cela, il élabore divers modèles, dont les mérites sont comparés au regard du cahier des charges économique, technique, ergonomique, sociologique ou psychologique du commanditaire, avant que le processus ne s'achève par la sélection du modèle le mieux adapté. Le modèle devient alors un « universel » censé satisfaire un besoin humain fondamental, quel que soit le lieu, le moment, la culture de l'individu appartenant à la classe d'utilisateurs visée. Un objet type est un «standard ».

Le major Kruse guide le travail pas à pas. En dehors de son chef, Shimura Tashichi 志村太七, le Japanese Architectural Staff ne compte que deux anglophones, les jeunes Akioka Yoshio 秋岡芳夫 (1920-1997) et Kaneko Tokujirō 金 子徳治郎. Chaque jour, ils sont mandatés par l'équipe auprès du major Kruse. Dans le bureau no 407, situé au $3^{\mathrm{e}}$ étage de l'immeuble Mitsubishi shōji 三菱商 事, quartier de Marunouchi (Tōkyō), ils lui soumettent les plans dessinés la veille par l'équipe. Sa personnalité bienveillante et ouverte n'empêche pas Kruse d'être un professionnel exigeant, inflexible au plan de la qualité. Chaque jour, il examine, critique et biffe chaque croquis, plan, prototype, les renvoyant au besoin sur la planche à dessiner pour une refonte totale. Il chaperonne les ingénieurs japonais tout au long du processus de conception des modèles types du dependents housing. 
Aussi éminents que soient les designers du Japanese Architectural Staff, les efforts fournis, y compris pour élaborer le dessin préparatoire des projets, en nombre astronomique, ne compensent pas la médiocrité de leurs compétences techniques. De leur propre aveu, ils se situent très loin des performances de l'équipe américaine.

Toujours est-il qu'à la fin mai 1946, en l'espace de trois mois à peine, les plans définitifs de tous les équipements sont achevés et livrés. Ils concernent :

- 30 modèles types de meubles.

- 120 modèles types d'ustensiles domestiques (de la vaisselle de table à l'électroménager).

- 20 modèles types de gros appareils, de la machine à laver électrique au radiateur à gaz.

Aussitôt, les prototypes sont présentés au grand public lors d'une exposition tenue au siège des grands magasins Mitsukoshi à Tōkyō, accompagnée d'une conférence du responsable de l'Industrial Arts Research Institute ${ }^{37}$.

$\mathrm{Au}$ Japon, c'est la toute première fois de l'histoire qu'un aussi large éventail de modèles d'objets pour la vie quotidienne, de type occidental et standardisé pour la production de grande série, voit le jour. Le programme a été remarquablement formateur pour le Japanese Architectural Staff. Toyoguchi Katsuhei 豊口克平 (1905-1991), responsable de la conception du mobilier, déclare peu après, en octobre 1946 :

$\mathrm{Au}$ résultat, nous, les responsables, sommes contents d'avoir trouvé là l'occasion de réaliser une gamme organisée et stylistiquement unifiée de meubles modernes, d'un type jamais vu au Japon auparavant. Cela nous a permis de prendre conscience du renouveau des techniques manufacturières, et nous a fourni d'amples informations sur la réalité du mode de vie occidental dont nous avions auparavant une idée floue, mais aussi sur les techniques de la conception formelle des meubles.

その結果は従来我が国では見られなかつた整然且つ統 一のある近代的なモ/とする事が出来た事は擔當者の吾

37. Koizumi Kazuko 小泉和子編 (dir.), op. cit., vol. 2 , 1999, p. 31. 


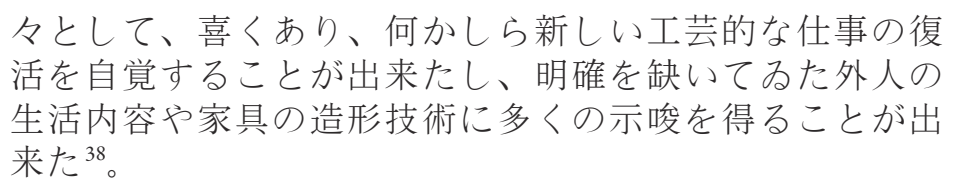

\section{6, année zéro de la production de masse standardisée}

Dans un premier temps, au vu de l'état de l'industrie japonaise et des ressources en matières premières, le GHQ estime impossible de faire fabriquer dans l'archipel. Il pense d'abord importer les biens nécessaires des États-Unis, mais il doit y renoncer faute de moyens de transport maritime. Il se résout alors à faire venir au Japon les stocks de matières premières disponibles dans les bases américaines du Pacifique, pendant qu'il enjoint au ministère japonais de l'Industrie et du Commerce de rassembler tout ce qu' il reste de forces vives parmi les manufactures de l'archipel. Sont ainsi réquisitionnées environ 300 entreprises - dont 150 à 160 basées à Tōkyō - pour le mobilier, et une cinquantaine pour l'électroménager et le gros appareillage, à commencer par les plus gros fabricants de l'avant-guerre : Tōshiba, Matsushita, Toyota, Hitachi, Mitsubishi, etc. C'est ainsi l'intégralité de l'infrastructure nationale dans les secteurs concernés qui est mobilisée par la fabrication des biens de consommation américains entre 1946 et $1948^{39}$.

L'impact sur l'industrie japonaise est également qualitatif. Une production de masse standardisée a vu le jour pendant la guerre grâce à l'industrie militaire. Dans le secteur du bois, la quasi-totalité de la production - boîtes à munitions, pièces de navires ou d'avions, avions-leurres pour tromper l'ennemi, etc. - était façonnée en lamellé collé, un procédé moderne dans lequel les manufactures ont acquis un bon niveau de compétence. Mais elles n'ont aucune expérience de la production de mobilier, en ignorent les techniques d'autant plus complexes qu'il

38. Toyoguchi Katsuhei 豊口克平, «Shinchūgun kazoku-yō jūtaku kagu no sekkei ni tsuite » 進駐軍家族用住宅家具の設計について (À propos du design du mobilier pour le logement des familles des forces d'occupation), Kögei nyūsu 工芸ニュース (L'actualité des arts industriels), vol. 14, n² 2, octobre 1946, p. 8.

39. Koizumi Kazuko 小泉和子編 (dir.), op. cit., vol. 2, 1999, p. 64. 
s'agit d'articles de type européen conçus pour la production en grande série. Force leur est de s'adapter au plus vite, tout en faisant le rude apprentissage de modes de production en accord avec les critères américains. Le fait est que le GHQ ne laisse passer aucun défaut de fabrication. À sa sortie d'usine, chaque article est inspecté dans le détail, de la qualité des matériaux à l'aspect des surfaces finies. S'il passe l'épreuve avec succès, l'article reçoit une étiquette en métal : « Made in Occupied Japan $\gg^{40}$, avant d'aller équiper les logements américains. La traversée de cette épreuve, qui a permis aux manufactures d'intégrer à un rythme accéléré des compétences nouvelles d'un haut niveau technique et satisfaisant des critères de qualité compétitifs, sera bientôt l'un des ressorts de l'expansion industrielle du Japon dans le monde.

Les délais initialement impartis à la construction des logements du Dependents Housing Program - rappelons qu'ils devaient être achevés en mars 1947 - ne sont pas respectés. La fabrication des équipements bénéficiant avantageusement de ce retard, la première tranche ( $56 \%$ du programme de production) est livrée en août 1947 ; la seconde (44\%), en mars 1948. Au total, sortent ainsi des usines japonaises:

Pour les meubles :

- 950000 unités pour le Dependents Housing Program,

- 300000 unités pour le troup housing (logement des troupes),

- des centaines de milliers d'unités (le nombre exact est inconnu) pour le logement des forces du Commonwealth (BCOF),

- des centaines de milliers d'unités (le nombre exact est inconnu) pour les administrations et autres bâtiments réquisitionnés. Pour les appareils électroménagers et les ustensiles domestiques :

- au minimum 900000 unités - chiffre très en deçà de la quantité totale effective, inconnue $^{41}$.

40. Institué par le GHQ, via la SCAPIN 1535 du 20 février 1947, le label « Made in Occupied Japan » devait, originellement, concerner les exportations, sur lesquelles il était obligatoire. Reconduit le 5 décembre 1949 par la SCAPIN 2061, son usage fut étendu à la consommation intérieure de l'archipel, jusqu'à son abolition en 1952, à la fin de l'occupation.

41. Koizumi Kazuko 小泉和子編 (dir.), op. cit., vol. 2, 1999, p. 60. 


\section{CIPANGO}

370

Cahiers d'études japonaises $n^{\circ} 21$

Noguchi Jurō 野口寿郎 commente :

Une condition préalable était que, pour chaque modèle de meuble, le façonnage soit fait exactement dans les mêmes conditions de matériaux et de techniques pour l'ensemble de la production. [...] Aussi chaque modèle de meuble a-t-il été dessiné par l'organisme d'État qu'est l'Industrial Art Institute, avec des collaborations privées, puis chacun des modèles a été fabriqué à l'identique, en grande série, au même moment à travers tout le territoire, par les principales manufactures régionales de meubles. Fabriquer ainsi, à la main, en masse, dans un même État, des objets de facture absolument identique constitue une prouesse sans précédent dans l'Histoire mondiale, y compris dans les États totalitaires, au plan de l'uniformisation de la production. [...] L'impact a été considérable pour les industries de production dans l'archipel. L'expérience est constitutive de la mise en place par l'État d'une politique de production de masse en matière de mobilier. Elle a amorcé la transition historique dans le mode de production, avec le passage de la culture artisanale à celle de l'ouvrier d'usine.

それは [...]一様の資材に、一様の工作が前提の基本設 計が必要であった。その設計図は民間の協力を得て政府 機関である製造工芸試験所で制作され、我が国全体地域 の主たる家具製造業が同型の家具を一斉に量産した。手 作り家具が一つの国家全体で画一量産されたこの実績 は、おそらく世界のどの全体主義国家にも例のない空前 絶後の生産統制の記録であつた。それは[…]生産工業に大 きい影響を残したものであろう。その経験がわが国家具 量産行為の一つの母体となつている。それはまた職人か ら工員への時代転換のはじめでもあつた螘。

42. Noguchi Jurō 野口寿郎, «Kagu, Furniture Industry - Sono shakai haikei no suii »家具一その社会背景の推移 (L'industrie du mobilier : les mutations de l'environnement sociétal), Kögei nyūsu 工芸ニュース (L'actualité de l'art industriel), vol. 39, $\mathrm{n}^{\circ} 4$, mars 1971, p. 42. 


\section{Du Made in Occupied Japan au Made in Japan}

L'intensité de l'effort accompli en seulement quelques mois insuffle un élan décisif à l'économie. Dans le domaine de l'industrie légère il permet, outre la reconstitution des infrastructures de production, la naissance d'une nouvelle branche : les biens de consommation durables modernes - c'est-à-dire à l'occidentale. Et, de façon corollaire, d'une science de l'ingénierie : le design pour l'industrie.

\section{8, « année zéro » du marché intérieur des biens de consommation durables}

Les premiers secteurs qui décollent, grâce à l'occupation, sont l'électroménager, les équipements de cuisine et les sanitaires (toilettes, baignoires, lavabos) ${ }^{43}$.

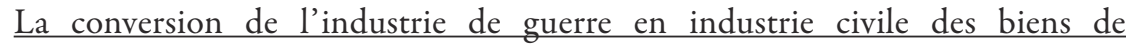
$\underline{\text { consommation durables }}$

Entre 1946 et 1948, les commandes du GHQ permettent la reconversion de l'industrie de guerre en industrie civile de temps de paix. Elles ont un impact décisif sur les manufactures, surtout en province, grâce à l'injection astronomique de capitaux qui accompagne les commandes, à l'approvisionnement en matières premières, et à l'apport gratuit de brevets.

43. Dans le secteur du mobilier, dans l'immédiat après-guerre, l'impact semble avoir été principalement technique et qualitatif car le redémarrage des industries ne fut pas toujours possible. Que le GHQ ait fourni les modèles à fabriquer avait été salvateur. Mais aucun fabricant japonais n'avait jamais, ni fait appel à un designer, ni possédé d'expérience suivie dans la fabrication d'articles de style occidental. Aussi, une fois achevées les commandes pour l'occupant, nombre de manufactures firent faillite, faute d'être parvenues à se tourner vers de nouvelles orientations. Par ailleurs, le marché japonais demeurait étroit, même si la construction d'immeubles collectifs à loyer bon marché par des centrales publiques ou privées, ayant soin d'équiper les cuisines à l'occidentale, y compris de chaises et tables, marque le début de la diffusion du mobilier au Japon, à partir de 1955. Pour survivre, en province, certains fabricants se regroupèrent sous forme d'union, qui leur permit de poursuivre la modernisation amorcée grâce au GHQ. Pour d'autres manufactures, tel Tendō mokkō 天堂木工, la mise en valeur de la haute technicité de leur production par la collaboration avec des designers extérieurs de grand renom, occidentaux ou japonais, a permis leur survie jusqu'aujourd'hui. 
372 Cahiers d'études japonaises n²1

Du jour au lendemain, les manufactures d'articles militaires, au chômage technique, voient arriver, par ordre du gouvernement japonais et avec l'aval du GHQ, non seulement des matériaux en quantité mais aussi le paiement d'acomptes s'élevant à $30 \%$ du montant total des commandes, avec la garantie du règlement du solde dans les 24 heures suivant la livraison : une manne inespérée qui permet à l'industrie d'opérer la mutation vers l'industrie civile.

Le redémarrage s'accompagne d'une modernisation radicale et profonde, alignée sur la haute technicité américaine, en particulier grâce à l'apprentissage - sans précédent dans les secteurs concernés - de la production de masse standardisée. La modernisation bénéficie du fait que le GHQ fournit les plans des modèles, autre facteur clé dans un pays où le design n'a pas encore pénétré l'industrie. De plus, ces modèles sont à la pointe de l'actualité technologique et des exigences des consommateurs. Ils positionnent l'industrie japonaise en concurrente de la production américaine sur le marché mondial, en exportateur à venir. La reconstruction est fulgurante : elle s'opère en dix-huit mois. La transition accomplie, les fabricants n'ont plus qu'à imiter les modèles américains pour continuer à se développer et à conquérir les marchés. Le ministère du Commerce et de l'Industrie (MITI) les y encourage à divers niveaux.

\section{La standardisation industrielle au Japon : une affaire d'État dès 1946}

En octobre 1945, le MITI dote l'Industrial Arts Research Institute d'un « Comité pour la standardisation des articles du commerce » Shōhin hyōjun iinkai 商品標 準委員会. Le terme 《articles du commerce » désigne ici les objets de la vie quotidienne, plus précisément les équipements domestiques. La mission du Comité est de concevoir les standards du marché intérieur. L'enjeu est de taille :

En plus de mieux rentabiliser les matériaux par la standardisation des articles du commerce, et rendre plus performante la vie de tous les jours, le projet est de refonder le mode de vie de nos concitoyens sur une base plus moderne [bunkateki 文化的] et plus rationnelle $[\ldots]$.

商品の標準化に依る原料資材の有効利用及び生活能率 
の向上を期すると同時に、国民生活の文化的、合理的再 建を圖ることとな $[る]^{44}$ 。

Le Comité dépend de l'Agence des brevets industriels (Tokkyo-kyoku 特許局) du ministère, créée en juin 1946. Dès lors, l'État s'attelle aux recherches sur la standardisation, au nom de l'industrie privée.

C'est la première fois que des travaux de cette envergure sur la standardisation sont accomplis en matière d'industrie civile pour le marché intérieur ${ }^{45}$. Que le projet, en décalage avec l'état du pays au moment de sa conception, émane du gouvernement, le colore d'un ton bureaucratique. Le gouvernement anticipe-t-il les effets de la collaboration avec le GHQ ? Les États-Unis possèdent une avance importante sur le reste du monde en matière de design industriel et d'industrie des biens de consommation durables. La production industrielle standardisée de masse, née au milieu du XIX ${ }^{\mathrm{e}}$ siècle, y est banalisée depuis le fordisme. Depuis, la technologie industrielle américaine est la plus moderne du monde. Elle a inspiré le Japon dès avant la guerre, dans tous les secteurs de l'équipement domestique : de l'ampoule électrique à l'électroménager, la production japonaise dépendait presque entièrement de brevets américains, sinon du partenariat avec les grandes firmes à commencer par Westinghouse et General Electric. À l'heure de l'occupation, le MITI semble vouloir à nouveau faire bénéficier son industrie des enseignements tirés de la collaboration. Il pilote une vaste opération de « recherche

44. SHŌKŌSHŌ KŌGEI SHIDōSHo 商工省工芸指導所編 (dir.), « Shōhin hyōjunka iinkai »商品標準化委員会 (Le comité de standardisation des articles du commerce), Kōgei nyūsu 工芸二ュース (L'actualité des arts industriels), vol. 14, nº 1, juin 1946, p. 21.

45. La notion même de «standardisation industrielle » est apparue entre 1921 - année de la création du Comité national d'élaboration de standards industriels, le Japan Industrial Standards Comittee 日本工業標準調査会 (JISC) - et 1922, quand sont publiées les premières normes standardisées. Dès lors, le mouvement de standardisation des pièces détachées produites en grande série s'étend, mais la standardisation ne s'applique pas à des modèles produits dans le secteur des biens de consommation durables, ce secteur ne connaissant pas avant 1945 la production en grande série. L'IARI a tenté quelques travaux pionniers, de caractère expérimental, à partir des années 1930, y compris à l'heure de la guerre pour l'industrie militaire. 
374 Cahiers d'études japonaises n²1

et développement » dans le secteur alors le plus prometteur de l'industrie japonaise : l'électroménager.

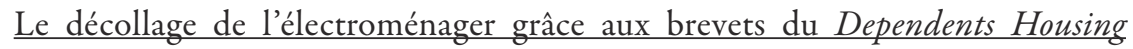
Program

Le MITI possède les droits sur les équipements du Dependents Housing Program, dont les brevets sont déposés auprès del'Agence des Brevets Industriels Standardisés (Tokkyo hyōjun-kyoku 特許標準局) de Tōkyō. À partir de la fin 1946, il diffuse à travers l'archipel les dessins, accompagnés des cotes et des explications concernant le mode de fabrication. Aux industriels qui souhaitent les reproduire à l'identique, il en offre gratuitement les plans détaillés ${ }^{46}$. Parallèlement, le MITI mène campagne pour la standardisation et la production de masse. Par exemple, il s'associe en 1947 avec Toshiba (fondé en 1904), la plus grande entreprise d'appareils électriques et électroniques, pour des recherches sur la finalisation de modèles se prêtant à la production mécanisée de grande série, accompagnées de campagnes d'études de marché et de design. Ces initiatives poussent des industriels d'autres secteurs d'activité à se reconvertir à leur tour vers le nouveau marché émergeant. L'industrie japonaise des biens de consommation durables est née.

ÉVOLUTION DU NOMBRE D’APPAREILS ÉLECTRIQUES PRODUITS AU JAPON AUSSITÔT APRÈS LA GUERRE

\begin{tabular}{|c|c|c|c|}
\hline Année & Lave-linge & Réfrigérateurs & Ventilateurs \\
\hline 1946 & 162 & 529 & 66282 \\
\hline 1947 & 1854 & 2574 & 74329 \\
\hline 1948 & 265 & 7771 & 77159 \\
\hline 1949 & 364 & 5312 & 95703 \\
\hline 1950 & 2328 & 4996 & 118804 \\
\hline 1951 & 3388 & 1998 & 173903 \\
\hline 1952 & 15117 & 3587 & 290879 \\
\hline
\end{tabular}

46. Voir Kōgei nyūsu 工芸ニュース (L'actualité de l'art industriel), n² 2, octobre 1946 ; n³, novembre-décembre 1946. 


\begin{tabular}{|c|c|c|c|}
\hline 1953 & 104679 & 7470 & 434585 \\
\hline 1954 & 265552 & 16990 & 561792 \\
\hline
\end{tabular}

Chiffres du MITI, Koizumi Kazuko 小泉和子編 (dir), Senryōgun jütaku no kiroku 占領軍住宅の記録 (Annales du logement des forces d'occupation), vol. 2, Tōkyō,

Sumai no toshokan shuppankyoku 住まいの図書館出版局, 1999, p. 102.

《Les 3 talismans » (sanshu no shinki 三種の神器) - lave-linge, réfrigérateur, aspirateur - deviennent les moteurs de l'essor économique fulgurant, connu sous le nom de «boom Jinmu » (Jinmu keiki 神武景気) à partir de la fin 1954. Les «3C »-colour television, cooler, car - prendront le relais à partir des années 1960. Avec un taux moyen annuel le plus souvent supérieur à $10 \%$ à partir de 1950, la croissance du PIB est deux fois et demie plus rapide que celle des États-Unis. Le Japon se rapproche de son objectif: rattraper le niveau économique de l'Occident. L'adoption des méthodes de marketing américaines, fondées sur la recherche de cycles de vie courts afin d'amplifier la concurrence, vient soutenir la croissance. Les Jeux olympiques de Tōkyō en 1964 voient le monde entier s'incliner devant les stratégies industrielles et commerciales du Japon. L'ère du « Made in Japan » a commencé.

\section{2, année zéro du design industriel japonais}

En avril 1951, Matsushita Kōnosuke 松下幸之助 (1894-1989) proclame dans la presse : « Nous sommes entrés dans l'ère du design ! » Il revient des États-Unis, où il a étudié pendant trois mois les industries électriques et électroniques de pointe, pour constater que les appareils américains se vendent au double du prix des japonais, et que la recette du succès tient en un mot : le design. C'est que la laideur se vend $\mathrm{mal}^{47}$, proclame au même moment le père du design industriel américain, Raymond Lœwy (1893-1986). Les firmes américaines possèdent un département de design intégré. Deux mois plus tard, Matsushita Kōnosuke 松下

47. Voir l'autobiographie de Raymond Loewy, Never Leave Well Enough Alone, New York, Simon and Schuster, 1951. 
幸之助 annonce la création d'un département 《 Design » au sein de son entreprise. La firme devient ainsi la première entreprise de l'histoire du Japon à recourir au design industriel. Ses concurrents (Toshiba, Hitachi, Mitsubishi...) l'imitent aussitôt.

En 1952, la «Japan Industrial Designers' Association (JIDA) » voit le jour. Elle est calquée sur le modèle de l' « American Society of Industrial Design (ASID) ». Le « Tōkyō Art Directors Club (Tōkyō ADC) », créé lui aussi en 1952, s'inspire pour sa part du « New York Art Directors Club ». Les institutions professionnelles naissent en cascade. Les années 1951 et 1952 marquent un tournant. Il s'agit de l'entrée dans l'ère du design industriel, dont le modèle américain est la référence sur tous les plans, non seulement institutionnel, mais aussi théorique, technique, et commercial. L'occupation des Alliés s'achève, l'ère «Peace $»^{48}$ commence - celle d'une consommation de masse parée de l'aura américaine.

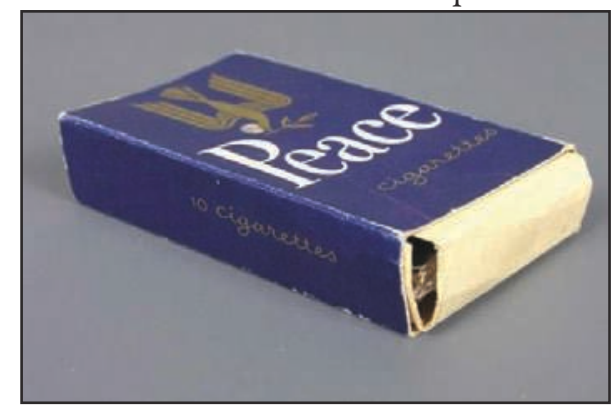

FIGURE 20.

Les cigarettes Peace (Japan Tobacco \& Salt Public Corporation), commercialisées à partir de 1946. L'emballage a été conçu, à la demande du Japon, en 1952, par le designer américain Raymond Lœwy.Source : Museo del Objeto del objeto, Mexico

48. Peace est le nom d'une marque japonaise de cigarettes, créée en janvier 1946. Devenues un des symboles les plus marquants de l'après-guerre japonais, ces « Gauloises du Japon » (surnom attribué par les Français) sont les cigarettes bon marché et populaires de l'aprèsguerre. L'emballage du paquet a été conçu en 1952 par l'Américain Raymond Loewy, sur invitation de la Japan Industrial Designers' Association (JIDA), l'association professionnelle des designers industriels japonais. Outre que, par son succès, le nouveau package fait s'envoler les ventes, les honoraires exorbitants (1,5 million de yens) facturés par Raymond Loewy contribuent à la reconnaissance de la profession de designer, jusqu'alors dépourvue de statut social et de valeur économique. En ce sens 1952 ajoute une pierre à l'institutionnalisation de l'industrie du design au Japon. 


\section{Conclusion}

Les modes de vie se sont transformés du tout au tout après la Seconde Guerre mondiale. La présence des forces d'occupation, les campagnes d'informations du GHQ et des institutions japonaises ont favorisé l'apprentissage de la culture matérielle occidentale et de son utilisation. Un marché s'est ouvert. Il a permis l'essor d'une industrie productrice de biens de consommation modernes, qui a vu le jour grâce au Dependents Housing Program. L'existence de ce programme a permis au Japon d'intégrer les techniques de production des objets de la modernité, de concevoir des modèles standardisés pour la production de masse et de les fabriquer avec une qualité irréprochable. L'industrie japonaise ne périclite pas une fois le programme du dependents housing achevé. Les brevets des équipements de ce dernier appartiennent à l'État japonais, qui les a financés, aussi les usines peuvent-elles continuer à se développer. Les brevets portant sur des produits de pointe, et la qualité des produits étant compétitive, l'industrie japonaise peut dès lors, outre satisfaire la demande intérieure, se lancer sur le marché des exportations. Le design, dont l'ingénierie avait été acquise auprès des Américains, permet quant à lui de développer une production japonaise originale qui, à partir des années 1960, conquiert la notoriété internationale sous le label Made in Japan.

\section{Bibliographie}

\section{Sources premières}

Casey Hugh J., United States far East Command (dir.), Dependents Housing: Japan \& Korea, Engineer Section F.E.C., 1949, 180 p.

Central Liaison Office, Memorandum for the Imperial Japanese Government: Survey of Foreign Type Residences in the Tokyo Area, Tōkyō, GHQ, 11 novembre 1945.

GHQ Design Branch Japanese Staff \& ShōKōshō Kōgei Shidōsho 商 工省工芸指導所編 (dir.), Dependents Housing in Japan ※ Korea デペンデ ントハウス 連合軍家族用住宅集図 (Le logement pour les familles des 
378 Cahiers d'études japonaises n² 21

troupes d'occupation au Japon et en Corée), Tōkyō, 技術資料刊行会 F.E.C., $1948,266 \mathrm{p}$.

KANEko Tokujirō 金子徳次郎, «Amerika no kagu wo Nihon de tsukuru koto - kurūze shōsa wo chūshin ni »アメリカの家具を日本で作ることーク ルーゼ少佐を中心に (Fabriquer du mobilier américain au Japon : autour du major Kruse), Kögei nyūsu 工芸二ュース (L'actualité des arts industriels), vol. $14, \mathrm{n}^{\circ} 2$, octobre 1946 , p. 18-23.

Raymond Antonin, An Autobiography, Rutland (Vermont), Charles E. Tuttle, $1973,328 \mathrm{p}$.

SAITō Shinji 齐藤信治, «Shinchūgun kazoku-yō kagu seisan no igi »進駐軍 家族用家具生産の意義 (L'intérêt de fabriquer le mobilier des familles des forces d'occupation), Kōgei nyūsu 工芸二ュース (L'actualité des arts industriels), vol. 14, $\mathrm{n}^{\circ} 2$, octobre 1946, p. 2-7.

SENRYŌGUN CHŌTATSUSHI HENSAN IINKAI 占領軍調達史編纂委員会編 著 (dir.), Senryōgun chōtatsushi 占領軍調達史 (Histoire de l'intendance des Forces d'occupation), vol. 1 : Senryōgun chōtatsu no kichō 占領軍調達の基 調 (Les grandes orientations de l'intendance des Forces d'occupation), Tōkyō, Chōtatsuchō 調達庁, 1956.

SENRYŌGUN CHŌTATSUSHI HENSAN IINKAI 占領軍調達史編纂委員会編 著 (dir.), Senryōgun chōtatsushi 占領軍調達史 (Histoire de l'intendance des forces d'occupation), vol. 2 : Geinōjubin kanzai 芸能 需品 管材 (Les arts du spectacle, les fournitures, la tuyauterie), Tōkyō, Chōtatsuchō 調達庁, 1957.

SENRYŌGUN CHŌTATSUSHI HENSAN IINKAI 占領軍調達史編纂委員会編 著 (dir.), Senryōgun chōtatsushi 占領軍調達史 (Histoire de l'intendance des forces d'occupation), vol. 3 : Kōji 工事 (Les travaux d'infrastructure), Tōkyō, Chōtatsuchō 調達庁, 1959. 
SHŌKŌSHŌ KŌGEI SHIDŌSHO 商工省工芸指導所編 (dir.), «Shōhin hyōjunka iinkai »商品標準化委員会 (Le comité de standardisation des articles du commerce), Kōgei nyūsu 工芸二ュース (L'actualité des arts industriels), vol. $14, \mathrm{n}^{\circ} 1$, juin 1946 , p. 21-22.

SHŌKŌSHŌ KŌGEI SHIDŌSHO 商工省工芸指導所編 (dir.), «Shōhin hyōjunka iinkai »商品標準化委員会 (Le comité de standardisation des articles du commerce), Kōgei nyūsu 工芸二ユース (L'actualité des arts industriels), vol. $14, \mathrm{n}^{\circ} 2$, octobre 1946 , p. 25 .

Supreme Commander for the Allied Powers, General Headquarters, History of the Nonmilitary Activities of the Occupation of Japan G H Q 日本占 領史, vol. 50 : Keikōgyō 軽工業 (L'industrie légère), Tōkyō, Nihon tosho sentā 日本図書センター, 1998 [1952].

Toyoguchi Katsuhei 豊口克平, « Shinchūgun kazoku-yō jūtaku kagu no sekkei ni tsuite 》進駐軍家族用住宅家具の設計について (À propos du design du mobilier pour le logement des familles des forces d'occupation), Kōgei nyūsu 工芸二ユース (L'actualité des arts industriels), vol. 14, n 2, octobre 1946, p. 8-17.

Van Staaveren Jacob, An American in Japan 1945-1948: A Civilian View of the Occupation, Seattle - London, University of Washington Press, 1994.

\section{Sources secondes}

Akio Satoko 秋尾沙戸子, Washington Heights. GHQ ga Tökyō ni kizanda sengo ワシントン・ハイツ・G H Qが東京に刻んだ戦後（Washington Heights : le GHQ a imprimé dans Tōkyō les fondements de l'après-guerre), Tōkyō, Shinchō-sha 新潮社, 2009.

Akioka Yoshio 秋岡芳夫, 《Shinchūgun-yō DH kagu no sekkei »進駐軍用 DH 家具の設計 (La conception du mobilier pour le dependents housing des forces d'occupation), in ZAIDAN HōjIN KōGEI ZAIDAN 財団法人・工芸 


\section{CIPANGO}

380

Cahiers d'études japonaises $n^{\circ} 21$

財団編 (dir.), Nihon no kindai dezain undoshi, 1940-nen kara 1980-nen 日 本の近代デザイン運動史 1940年〜1980年 (Histoire du mouvement du design moderne au Japon, 1940-1980), Tōkyō, Perikan-sha ペりかん社, 1990, p. 9-11.

Amemrya Shōichi 雨宮昭一, Senji sengo taisei ron 戦時戦後体制論 (Le régime sous la guerre et dans l'immédiat après-guerre), Tōkyō, Iwanami shoten 岩波 書店, 1997.

Amiтo Takeo 網戸武夫, Kenchiku, keiken to moraru - Sone Tatsuzō, Chūjō Seiichirō, Nakamura Junpei, Kume Gonkurō to watashi 建築 経験と モラルー曾襧達蔵 中条精一郎 中村順平 久米権九郎と私 (Architecture, expérience et morale : Sone Tatsuzō, Chūjō Seiichirō, Nakamura Junpei, Kume Gonkurō et moi), Tōkyō, Sumai no toshokan shuppan-kyoku 住まいの図書館出版局, 1999.

Cohen Jerome B., Hunter Janet (dir.), Japanese Economic History 1930-1960, vol. 2, New York - London, Routledge [première édition : Japan's Economy in War and Reconstruction, University of Minnesota Press], 2000 [1949].

Dees Bowen C., The Allied Occupation and Japan's Economic Miracle: Building the Foundations of Japanese Science and Technology, London, Routledge, 1997.

Dower W. John, Embracing Defeat: Japan in the Wake of World War II, New York, Norton \& Company - The New Press, 1999.

FAILlACE Gaetano フェーレイス・ジャエ夕ーノ, Makkāsāa no mita yakeato マッカーサーの見た焼け跡 (Les ruines des bombardements incendiaires telles que McArthur les a vues), Tōkyō, Bungei shunjū文芸春秋, 1983.

Gossot Anne, «"Gaz et électricité à tous les étages" : les débuts des industries électriques et électroniques », Les Cabiers d’Ebisu, nº 1, Tōkyō, UMIfre 19 Maison franco-japonaise, 2010, p. 5-32. 
KoIzumi Kazuko 小泉和子編 (dir.), Senryōgun jūtaku no kiroku 占領軍住宅 の記録 (Annales du logement des forces d'occupation), 2 vol., Tōkyō, Sumai no toshokan shuppankyoku 住まいの図書館出版局, 1999.

Loewy Raymond, Never Leave Well Enough Alone, New York, Simon and Schuster, 1951.

Masunari Kazutoshi 増成和敏, « Matsushita Kōnosuke no seihin dezain ni taisuru kangaekata to un.ei »松下幸之助の製品デザインに対する考え 方と運営 (La philosophie de Matsushita Kōnosuke en matière de design produit et de management), Dezain-gaku kenkyū, Kenkyū ronbunshū デザイン 学研究 研究論文集 (Études de designologie: actes de la recherche), vol. 58, $\mathrm{n}^{\circ} 1,2011$, p. 59-66.

Matsuo Takayoshi 松尾尊公, Nihon no rekishi, vol. 21 : Kokusai kokka e no shuppatsu 日本の歴史（21)国際国家への出発, Tōkyō, Shūeisha 集英社, 1993.

MORI Hitoshi 森仁史, Nihon «kōgei »no kindai - Bijutsu to dezain no bodai toshite 日本「工芸」の近代一美術とデザインの母胎として (Les arts industriels à l'ère moderne : en tant que matrice des arts plastiques et du design), Tōkyō, Yoshikawa kōbunkan 吉川弘文館, 2009.

Murakami Hyōe, Japan: the Years of Trial 1919-1952, Tōkyō - New York, Kōdansha International, 1982.

NogUCHI Jurō 野口寿郎, « Kagu, Furniture Industry - Sono shakai haikei no suii » 家具一その社会背景の推移 (L'industrie du mobilier : les mutations de l'environnement sociétal), Kögei nyūsu工芸ニュース (L'actualité de l'art industriel), vol. 39, $\mathrm{n}^{\circ} 4$, mars 1971 , p. $42-46$.

OKahara Miyako 岡原都, Amerika senryōki no minshuka seisaku アメリカ 占領期の民主化政策 (Les mesures de démocratisation sous l'Occupation américaine), Tōkyō, Akashi shoten 明石書店, 2007. 


\section{CIPANGO}

382 Cahiers d'études japonaises n² 21

Okahara Miyako, Sengo nihon no media to shakai kyöiku - «Fujin no jikan » no hōsō kara «NHK fujin gakkyū »no shüdan gakushū made 戦後日本のメデ イアと社会教育一「婦人の時間」の放送から「NHK婦人学級」の 集団学習まで (Médias et éducation du grand public après la guerre : depuis l'émission «L'heure des femmes » jusqu'aux cours collectifs « Les classes de la NHK pour les femmes »), Tōkyō, Fukumura shuppan 福村出版, 2009.

Sandler Mark H. (dir.), The Confusion Era: Art and Culture of Japan during the Allied Occupation 1945-1952, Seattle, University of Washington Press, 1997.

SATō Yōichi 佐藤洋一, Senryōka no Tōkyō 占領下の東京 Occupation Forces in Tōkyō 1945-52 (Tōkyō sous l'occupation), Tōkyō, Kawade shobō shinsha 河 出書房新社, 2006.

Sugas AWA Mitsumasa 菅澤光政, Tendō mokkō 天童木工 (L'entreprise Tendō mokkō), Tōkyō, Bijutsu shuppansha 美術出版社, 2008.

Ward Robert E., Sakamoto Yoshikazu (dir.), Democratizing Japan: the Allied Occupation, Honolulu, University of Hawaii Press, 1987.

YAMADA Shōgo 山田正吾, Kaden konjaku monogatari 家電今昔物語 (l'Électroménager jadis et naguère), Tōkyō, Sanseidō 三省堂, 1983.

Résumé : Au Japon, le design industriel apparaît entre 1945 et 1955 . Sa genèse est constitutive de celle des biens de consommation modernes/occidentalisés, dont le secteur industriel éclot à la fin des années 1940. Le processus fondateur s'ancre dans l'occupation de l'archipel par les forces alliées. À partir de sources d'époque et des analyses de spécialistes japonais, l'article en éclaire les modalités, jusqu'à l'intégration du mass production system américain comme ressort de la compétitivité industrielle japonaise au cours des décennies suivantes. Pendant l'occupation, c'est sous la direction d'ingénieurs américains, et à l'occasion de la conception de logements destinés aux troupes d'occupation aux standards de la middle class américaine, que, non seulement des ingénieurs japonais se forment 
aux techniques de pointe du design industriel, mais aussi que l'industrie japonaise s'initie à la fabrication en grande série standardisée. Dernière étape du processus : la constitution d'un marché, national cette fois, des nouveaux biens de consommation, fruit des campagnes de propagande pour l'american way of life. L'occupation a rassemblé les conditions du décollage de l'industrie du design japonais, et, avec elle, de l'industrie des biens de consommation «à l'américaine ».

Mots-clés : Japon, occupation des forces alliées, design, industrie des biens de consommation, dependents housing, american way of life, made in occupied Japan

Abstract: Japanese industrial design appeared between 1945 and 1955. Its genesis is linked to that of the modern/Westernized consumer goods, an industrial sector which blossomed in the late 1940s. Its founding process stems from the occupation of the archipelago by the Allied Forces. Based on contemporary sources and analyses by Japanese specialists, this article highlights the steps of that process, up to the integration of the American mass producing system used as the model for Japanese industrial competitiveness over the following decades. During the occupation, Japanese engineers undergo training under the direction of American engineers, as they design housing for occupation troops, which must meet the standards of the American middle-class. These Japanese engineers are trained to the state-of-the-art techniques of industrial design, all the while the Japanese industry starts resorting to large-scale standardized manufacturing. The last stage of the process is the establishment of a market for consumer goods, but a national one this time, a natural outcome of the propaganda campaigns for the American way of life. The occupation offered the right conditions for the Japanese design industry to take off, bringing in its stead the industry of "Americanstyle" consumer goods.

Keywords: Japan, Allied Forces Occupation, Design, Consumer Goods Industry, Dependents Housing Programme, American Way of Life, Made in Occupied Japan

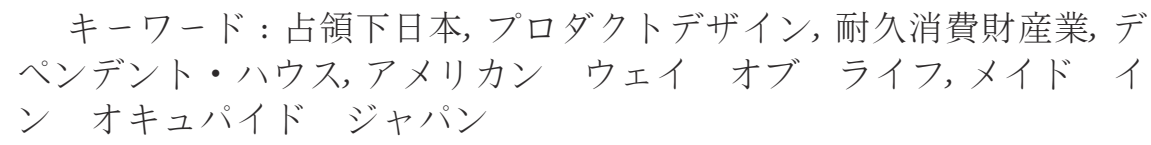


